Article

\title{
An Empirical Study on Design Partner Selection in Green Product Collaboration Design
}

\author{
Aijun Liu ${ }^{1,2}$, Haiyang Liu ${ }^{1, *}$, Yaxuan Xiao ${ }^{1}$, Sang-Bing Tsai ${ }^{3,4, *}$ (i) and Hui Lu ${ }^{5}$ \\ 1 Department of Management Engineering, School of Economics \& Management, Xidian University, \\ Xi'an 710071, Shaanxi, China; ajliu@xidian.edu.cn (A.L.); xiaoyaxuan@stu.xidian.edu.cn (Y.X.) \\ 2 State Key Laboratory for Manufacturing Systems Engineering, Xi'an Jiaotong University, \\ Xi'an 710049, Shaanxi, China \\ 3 Zhongshan Institute, University of Electronic Science and Technology of China, \\ Zhongshan 528400, Guangdong, China \\ 4 Economics and Management College, Civil Aviation University of China, Tianjin 300300, China \\ 5 Tianhua College, Shanghai Normal University, Shanghai 201815, China; janetluck@126.com \\ * Correspondence: ocean@stu.xidian.edu.cn (H.L.); sangbing@hotmail.com (S.-B.T.); \\ Tel.: +86-0760-8832-8103 (S.-B.T.)
}

Received: 28 November 2017; Accepted: 3 January 2018; Published: 8 January 2018

\begin{abstract}
Green production has become an important issue in PCD (Product Collaboration Design) for almost every enterprise, and will determine the sustainability of enterprises in the long term. The choice of design partner is a necessary condition in order to achieve green production. For the uncertain, fuzzy, and dynamic information such as unknown indices and weights, fuzzy semantics, and dynamic time factors in GPCD (Green Product Collaboration Design), a two-stage dynamic hybrid MADM (Multi-Attribute Decision Making) approach based on fuzzy DEMATEL (Decision-Making and Trial Evaluation Laboratory), fuzzy KMA (Karnik-Mendel Algorithm), and fuzzy VIKOR (VlseKriterjumska Optimizacija I Kompromisno Resenje) was proposed. In the first stage, fuzzy DEMATEL was used to determine the evaluation indices. Then, in the second stage, to accurately depict the dynamic information generated by the different phases of a product design, the dynamic evaluation method based on fuzzy theories was employed, and the weights of the indices were calculated by fuzzy KMA, then sorted by fuzzy VIKOR. Finally, a case study and a comparative analysis wre provided to illustrate the effectiveness of the proposed approach.
\end{abstract}

Keywords: design partner selection; green product; fuzzy DEMATEL; fuzzy KMA; fuzzy VIKOR; dynamic hybrid MADM; sustainability; sustainable operation

\section{Introduction}

Green product refers to the production process and its own energy saving, water saving, low pollution, low toxicity, renewable, and recyclable products. Under the influence of economic globalization, market competition is becoming increasingly fierce. In the face of a complex and volatile economic environment as well as diversified and personalized customer needs, Product Collaboration Design (PCD) is the inevitable choice for enterprise survival and development [1]. Camarinha-Matos and Afsarmanesh [2,3] proposed an effective way to integrate the product, supplier, research organization, and other units to complete product design, namely PCD. Nowadays, green and sustainability are the two main themes of business/social development [4-11]. Green products, as its security and social benefits are protected, are much loved and sought after. At the same time, green enterprises are inclined by the policy of relevant government departments, thus have a broader space for development and prospects. To protect the efficiency and effect of product design, the cooperation between enterprises is usually adopted [12,13]. At present, the research on green PCD is fairly rare, 
the few studies on PCD mainly focus on the collaborative design model and collaborative resource conflict detection and digestion. These studies have proven to be the key to the success of the PCD [14].

In PCD modeling research, Huang et al. [15] studied the design process modeling method based on hierarchical Colored Petri Nets (CPN) in allusion to the characteristics that the current collaborative design process mainly analyzes the qualitative features and lacks quantitative analysis. Feng et al. [16] conducted a modular analysis based on process projects construction procedures, and presented an effective heterogeneous design data management model in an integrated data management and storage architecture. In view of the classification of various emergencies, Xing et al. [17] studied the dynamic coordination strategy for design tasks based on event and cycle hybrid driven models. A coordination efficiency model considering accidents in PCD was constructed. Yang et al. [18] proposed a multi-objective PCD model with the minimum completion time and the minimum tardiness penalties. Liu et al. [19] put forward a new two-stage method to achieve PCD. In this method, customer satisfaction was maximized based on the fuzzy multi-criteria decision and the quality function deployment.

In the research of collaborative resource conflict detection and digestion, Zhu and Song [20] analyzed the complex relationship affecting the parallel operation, and proposed a conflict detection algorithm based on the design history. Hepworth et al. [21] proposed a method that could keep the model independent and achieve synchronization between distributed computer aided designs. Cheng et al. [22] proposed a meta-operation conflict resolution method to construct a feature-based collaborative design system. Yang et al. [23] studied the characteristics of food collaborative design and detected the known constraints by an interval propagation algorithm, then proposed a detection method based on a BP (back propagation) neural network of an unknown constraint set.

The above related literature only reviewed and studied the progress or later stages of PCD, which were mainly focused on the conflict and resolution of collaborative design modeling and the conflict of collaborative resources. However, few scholars have studied design partner selection issues early in the product design process, especially for green products and green sustainable cooperative units. As a matter of fact, in the competitive global business environment, the demand for green products is becoming more intense. To adapt to these trends, an environmental impact assessment should be considered as an important factor in the development phase of new products, in addition to the cost and quality of the product [24]. Therefore, the design and development of green products has attracted the attention of many scholars [25-28]. Green and sustainable product design partners, as an important part of the collaborative design of green products, need to be studied in depth. Furthermore, the type of green product produced, how it is produced, the quality of the product, the functional and commercial benefits, etc., are issues closely related to the design partners. Chandrasegaran et al. [29] pointed out that for the entire PCD process, decisions made early in the design process had a higher impact on energy, cost, and sustainability. Therefore, in the early stage of product design, it is necessary to conduct a comprehensive and effective assessment of the design partners in terms of quality, cost, greenness, and sustainability.

With regard to the fact that the product design partner is an essential part of green PCD that cannot be overlooked and should be studied, the choice of partners is related to the performance of green PCD, so the selection of a suitable design partner is necessary. In this paper, a hybrid Multi-Attribute Decision Making (MADM) method, considering dynamic time factor, was used to select the design partner in the process of green PCD. The hybrid method could deal with the interdependencies among various criteria in a fuzzy environment. The main contributions of this paper are listed as follows: (1) A hybrid method was developed to deal with MADM problems; (2) Dynamic time factors across different product design stages were considered, so the evaluations of the objects were more objective and comprehensive, and the evaluation results closer to the actual situation of PCD; (3) In view of the uncertainty of the green product design process and the subjective assumption of personal decision-making, fuzzy language set, vague language, and group decision-making methods were used to effectively avoid partially missing decision-making information; (4) It provides an objective and 
comprehensive new method and new idea for actual production enterprises to select partners who meet their requirements for sustainable development and green concept, and it can also be used for reference to other manufacturing enterprises.

The remainder of this article is arranged as follows. Section 2 is the analysis of the relevant literature related to the MADM problem or methods. Section 3 conducts the process of the two-stage hybrid decision model. Section 4 provides an example to validate the effectiveness of the proposed method. Section 5 is the comparative analysis and discussion. Finally, some conclusions and relevant prospects are presented in Section 6.

\section{Literature Review}

Throughout the literature, scholars have researched less on the choice of design partners, and more on supplier selection. There are obvious differences between the selection of design partners and the selection of suppliers. It is a MADM problem involving dynamic time factor, uncertainty, and the subjectivity of decision-making. The research worth reviewing is on the research of supplier selection, including a single MADM method and a hybrid MADM method.

Mardani et al. [30] reviewed a total of 393 articles published from 2000 to 2014 in more than 120 peer reviewed journals (extracted from Web of Science), and found that energy, environment, and sustainability were ranked as the first areas to have applied MADM techniques and approaches. Zavadskas et al. [31] summarized the literature related to hybrid MADM application, and the hybrid method was identified as an improvement of decision-making related to sustainability, and also promoted the future application of these methods. In the study of evaluation and decision-making methods for MADM problems, Govindan et al. [32] analyzed the literature from 1997 to 2011, and concluded that most of the previously applied techniques were based on fuzzy single-model methods. These single methods included: fuzzy Decision-Making and Trial Evaluation Laboratory (DEMATEL) [33-35]; fuzzy Karnik-Mendel Algorithm (KMA) [36-38]; fuzzy VlseKriterjumska Optimizacija I Kompromisno Resenje (VIKOR) [39-41]; fuzzy TOPSIS (Technique for Order Preference by Similarity to Ideal Solution) [42-44]; fuzzy AHP (Analytic Hierarchy Process) [45,46]; fuzzy ANP (Analytic Network Process) [47-49]. Zavadskas et al. [50] analyzed the papers referred to in the Thomson Reuters Web of Science Core Collection academic database, then concluded that hybrid MADM approaches, due to their abilities in integrating different techniques, could assist in handling miscellaneous information taking into account stakeholders' preferences. Keshavarz et al. [51] reviewed those published in peer-reviewed journals from 2001-2016 years, and concluded that the (ANP) and the TOPSIS method were the most commonly used methods.

In recent years, the hybrid decision-making method has become a significant research topic. Freeman and Chen [52] combined the AHP of the entropy method to calculate the weights, and used the TOPSIS method to convert the order preference technology into the supplier's prioritization. Kar [53] combined fuzzy set theory, AHP, and neural network to study the problem of supplier selection, and proposed a hybrid decision method to support group decision supports. Büyüközkan and Çifçi [54] presented a novel hybrid fuzzy MADM model combined with fuzzy DEMATEL, ANP, and TOPSIS to build an evaluation framework for green suppliers in a fuzzy environment. Tadić and Krstić [55] developed a novel hybrid MADM model that combined fuzzy DEMATEL, fuzzy ANP, and fuzzy VIKOR methods. Liou et al. [56] proposed a new hybrid model based on the DEMATEL method, ANP, and gray relation to solve the dependencies among various standards and the fuzzy information of decision makers. Yazdani et al. [57] put forward an integrated approach for green supplier selection based on the DEMATEL method, QFD (quality function deployment), and COPRAS (complex proportional assessment) by considering various environmental performance requirements and criteria. The key functions of green supply chain management are internal improvement and green supplier selection. Table 1 shows the methods used in the above literature.

To the best of our knowledge, there has not been any research that combined fuzzy DEMATEL, fuzzy KMA, and fuzzy VIKOR thus far for MADM problems such as design partner selection. 
Moreover, the current decision-making on suppliers is so concerned about the method of research that it has ignored the impact of time factors on the evaluation. However, in the process of PCD, the time factor cannot be ignored as the main design requirements are different in different design stages. In this paper, a two-stage dynamic hybrid MADM method was proposed to resolve the uncertainty of the design subject selection index, the ambiguity of evaluation information, and the dynamic of evaluation information at different design stages.

Table 1. Summary of some relevant research on green supplier selection.

\begin{tabular}{|c|c|c|}
\hline Category & Method or Model & Literature \\
\hline \multirow{6}{*}{ single-model methods } & fuzzy DEMATEL & $\begin{array}{l}\text { Chang, Chang \&Wu, 2011; Hsu, Kuo, Chen, \& Hu, 2013; } \\
\text { Lin, } 2013\end{array}$ \\
\hline & fuzzy KMA & $\begin{array}{l}\text { Mendel, 2013; Salaken, Khosravi, \& Nahavandi, 2016; Chen, } \\
\text { John, Twycross, \& Garibaldi, } 2017\end{array}$ \\
\hline & fuzzy VIKOR & $\begin{array}{l}\text { Boran, Genç, Kurt, \& Akay, 2009; Wang, Cheng, \& Huang, } \\
\text { 2009; Zouggari \& Benyoucef, 2009 }\end{array}$ \\
\hline & fuzzy TOPSIS & $\begin{array}{l}\text { Shemshadi, Shirazi, Toreihi, \& Tarokh, 2011; Sanayei, Mousavi, } \\
\text { \& Yazdankhah, 2010; You, You, Liu, \& Zhen, } 2015\end{array}$ \\
\hline & fuzzy AHP & Güngör, Serhadlıŏglu, \& Kesen, 2009; Kilincci \& Onal, 2011 \\
\hline & fuzzy ANP & $\begin{array}{l}\text { Guneri, Cengiz, \& Seker, 2009; Bhattacharya, Mohapatra, } \\
\text { Kumar, Dey, Brady, Tiwari, \& Nudurupati, 2014; Büyüközkan } \\
\text { \& Çif̧̧i, } 2012\end{array}$ \\
\hline \multirow{5}{*}{ hybrid decision-making methods } & AHP + TOPSIS & Freeman \& Chen, 2015 \\
\hline & AHP + neural network & Kar, 2015 \\
\hline & DEMATEL + ANP + TOPSIS & Büyüközkan \& Çifçi, 2012 \\
\hline & DEMATEL + ANP + VIKOR & Tadić, Zečević, \& Krstić, 2014 \\
\hline & DEMATEL + ANP + GRA & Liou et al. 2016 \\
\hline
\end{tabular}

\section{Proposed Hybrid Decision Model}

Combining qualitative and quantitative analysis, based on the fuzzy DEMATEL method, fuzzy KMA, and fuzzy VIKOR method, this paper proposed a two-stage dynamic hybrid design subject selection model. The following explains the computational steps of the hybrid MADM model that were developed in this paper. The general view of the proposed model is shown in Figure 1.

In the first stage, fuzzy DEMATEL is used to analyze the influence degree between the indices to screen for the important evaluation indices, thus narrowing the selection range of the design partner. In the second stage, we used fuzzy language and fuzzy number to characterize the fuzzy evaluation behavior of experts, consider the dynamic change of evaluation information in different design stages, and the bounded rationality of expert personal decision, and the DIFWG (Dynamic Intuitionistic Fuzzy Weighted Geometric Operator) was employed to integrate the same expert. Afterwards, we used the IFOWA (Intuitive Fuzzy Ordered Weighted Average Operator) to integrate the evaluation information on different experts, then determined the weights of the evaluation indices by fuzzy KMA, and finally were sorted and selected with fuzzy VIKOR. 


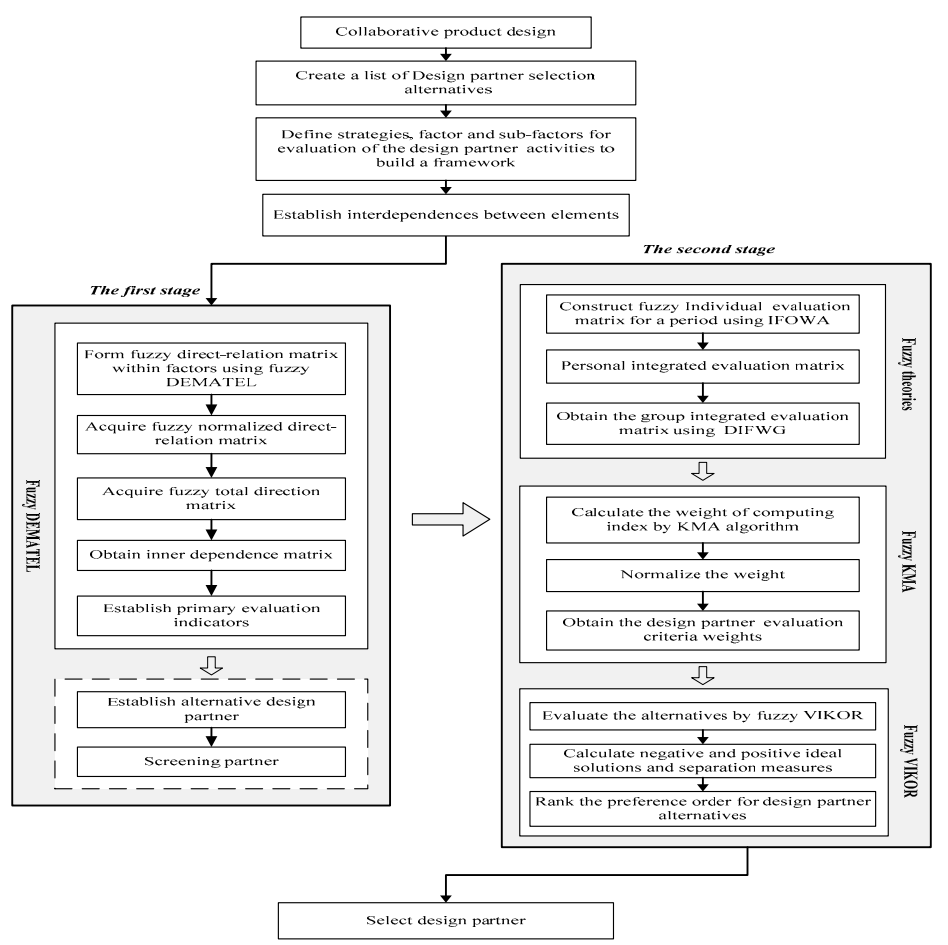

Figure 1. The two-stage dynamic hybrid selection model of design partner selection.

\subsection{Definitions and Operators}

Definition 1. Let $a=\left(\mu_{A}(x), v_{A}(x)\right)$ be an intuitive fuzzy number. Its score function $S(a)$ and precise function $H(a)$ are separately denoted as below:

$$
\begin{aligned}
& S(a)=\mu_{A}(x)-v_{A}(x) \\
& H(a)=\mu_{A}(x)+v_{A}(x)
\end{aligned}
$$

Definition 2. Let $a_{1}=\left(\mu_{1}, v_{1}\right)$ and $a_{2}=\left(\mu_{2}, v_{2}\right)$ be two intuitive fuzzy numbers. Their corresponding score functions are $S\left(a_{1}\right)$ and $S\left(a_{2}\right)$, the corresponding precise functions are $H\left(a_{1}\right)$ and $H\left(a_{2}\right)$. if $S\left(a_{1}\right)<S\left(a_{2}\right)$, then $a_{1}<a_{2}$; if $S\left(a_{1}\right)=S\left(a_{2}\right)$, and $H\left(a_{1}\right)=H\left(a_{2}\right)$, then $a_{1}=a_{2} ;$ if $H\left(a_{1}\right)<H\left(a_{2}\right)$, then $a_{1}<a_{2}$.

DIFWG. Let $a\left(t_{k}\right)=\left(\mu_{t_{k}}, v_{t_{k}}\right)(k=1,2, \ldots, p)$ be intuitive fuzzy number indifferent stages $t_{k}$, and $\eta(t)=\left(\eta\left(t_{1}\right), \eta\left(t_{2}\right), \ldots, \eta\left(t_{p}\right)\right)^{T}$ is the weight vector $t_{k}$ of the stage sequence and $\eta\left(t_{k}\right) \in[0,1], \sum_{k=1}^{p} \eta\left(t_{k}\right)=1$. $\operatorname{DIFWG}_{\eta(t)}\left(a\left(t_{1}\right), a\left(t_{2}\right), \ldots, a\left(t_{p}\right)\right)$ can be defined as follows:

$$
\operatorname{DIFWG}_{\eta(t)}\left(a\left(t_{1}\right), a\left(t_{2}\right), \ldots, a\left(t_{p}\right)\right)=\left(\prod_{k=1}^{p} \mu_{t_{k}} \eta\left(t_{k}\right), 1-\prod_{k=1}^{p}\left(1-v_{t_{k}}\right)^{\eta\left(t_{k}\right)}\right)
$$

IFOWA. Let $a_{\delta(j)}=\left(u_{\delta(j)}, v_{\delta(j)}\right)$ be the jth element in $a_{j}=\left(\mu_{j}, v_{j}\right) . \omega_{j}(j=1,2, \ldots, n)$ is the weight vector (position vector), which is associated with the IFOWA operator, where $\omega_{j} \geq 0, j=1,2, \ldots, n$, and $\sum_{j=1}^{n} \omega_{j}=1$.

$$
\operatorname{IFOWA} A_{\omega}\left(a_{1}, a_{2}, \ldots, a_{n}\right)=\left(1-\prod_{j=1}^{n}\left(1-u_{\delta(j)}\right)^{\omega_{j}}, \prod_{j=1}^{n} v_{\delta(j)} \omega_{j}\right)
$$




\subsection{Proposed Methods}

\section{(1) Fuzzy DEMATEL}

As an analytical method to solve complex problems, DEMATEL is very suitable for dealing with MADM problems in a fuzzy environment. DEMATEL technology builds a structural model analysis method used in the thinking process of the relation matrix, and related mathematical theory affects every element involved in the causal relationship to calculate the Markov Boolean and solve complex problems [56]. The application steps are as follows:

Step 1.1. Design fuzzy linguistic scale for evaluations. Relationships among the structure elements are defined using expert opinions through pairwise comparison. For the purpose of measuring the relationships between elements, it is required to design the linguistic scale with corresponding triangular fuzzy numbers (Table 2).

Table 2. The correspondence of linguistic terms and linguistic values.

\begin{tabular}{cc}
\hline Linguistic Terms & Linguistic Values \\
\hline No influence $(\mathrm{N})$ & $(0,0,0.25)$ \\
Low influence $(\mathrm{L})$ & $(0,0.25,0.50)$ \\
Medium influence $(\mathrm{M})$ & $(0.25,0.50,0.75)$ \\
High influence $(\mathrm{H})$ & $(0.50,0.75,1.00)$ \\
Very high influence $(\mathrm{VH})$ & $(0.75,1.00,1.00)$ \\
\hline
\end{tabular}

Step 1.2. Establish the direct impact relation matrix of the target layer elements $T_{m \times m}$. On the basis of the extensive collection of relevant information and expert opinions, we determine the relationship between various factors, expressed in the form of triangular fuzzy numbers.

Step 1.3. Singularize intuitionistic fuzzy numbers. IF $\widetilde{a}=\left(l_{i j}, m_{i j}, u_{i j}\right)$ is a triangular fuzzy number, then the new elements $T^{o}{ }_{i j}$ is obtained by the following formula [58].

$$
T_{i j}^{o}=\frac{l_{i j}+4 m_{i j}+u_{i j}}{6}
$$

Step 1.4. Normalize the direct relationship matrix. A normalized direct-relation matrix $S$ is obtained by using:

$$
S=K \times T
$$

where

$$
K=\min \left[\frac{1}{\max \sum_{j=1}^{m} a_{i j}}, \frac{1}{\max \sum_{i=1}^{m} a_{i j}}\right]
$$

Step 1.5. A total-relation matrix $M$ is calculated by using the following formulas:

$$
M=X(I-X)^{-1}
$$

Step 1.6. Calculate the degree of influence of each index $Y_{a}=D$, affected degree $Y_{b}=R$, as well as the center degree $Y_{c}=(D+R)$, and the reason degree $Y_{d}=(D-R)$ by the following formula:

$$
\begin{gathered}
D=\left[\sum_{j=1}^{m} s_{i j}\right]_{m \times 1} \\
R=\left[\sum_{i=1}^{m} s_{i j}\right]_{1 \times m}
\end{gathered}
$$

$s_{i j}$ represents the degree that the direct and indirect impact of the elements $i$ on the elements $j$. 
$D$ is the m-dimensional column vector composed of the sum of the elements of each row, and expressed as the combined effect of an element on the other elements.

$R$ is the m-dimensional row vector composed of the sum of the elements of each column, and expressed as a factor affected by the other elements.

$(D+R)$ reflects the relative importance of each element. The greater the value, the more important it is relative to other factors.

$(D-R)$ represents the relative influence of each element. The greater the value, the greater the impact on other factors, but is less affected by other factors.

Step 1.7. Let $Y_{c}$ and $Y_{d}$ be the main screening criteria. Set the initial values $Y_{c}{ }^{o}$ and $Y_{d}{ }^{o}$, they represent the critical values of the center degree and cause degree, respectively. In order to obtain the key evaluation indices, only indicators greater than $Y_{c}{ }^{0}$ or $Y_{d}{ }^{0}$ were retained.

Step 1.8. On this basis, the design partner can be screened by combining with experts' advice. After obtaining the evaluation indices, we asked the experts in relevant fields to make a dynamic fuzzy evaluation of the design partner for these indices.

\section{(2)}

\section{Fuzzy KMA}

The KMA is the most commonly used iterative type reduction method in fuzzy sets and systems, as well as new techniques for computing the fuzzy weighted average (FWA), by which we can obtain the objective optimal weight [59]. Based on this algorithm, the centroid interval of $w_{j}$ is calculated as follows:

Step 2.1. The intuitionistic fuzzy number is transformed into the form of interval numbers, e.g., $\left(\mu_{i j}, v_{i j}\right)$ can be recorded as the number of intervals in the form of $\left(L_{i j}, U_{i j}\right)$ and is shown as:

$$
L_{i j}=\mu_{i j}, U_{i j}=1-v_{i j}
$$

Step 2.2. Calculate the weight of the indicator $C_{j}$ and the upper limit of the weight. Calculate the lower limit $\underline{C}\left(\omega_{j}\right)$ and the upper limit $\bar{C}\left(\omega_{j}\right)$ of the weight of the indicator $C_{j}$.

$$
\begin{gathered}
\underline{C}\left(\omega_{j}\right)=\min _{\gamma \in[0,1]} \frac{\int_{0}^{\gamma} x U_{(j)} d x+\int_{\gamma}^{1} x L_{(j)} d x}{\int_{0}^{\gamma} L_{(j)} d x+\int_{\gamma}^{1} U_{(j)} d x} \\
\bar{C}\left(\omega_{j}\right)=\max _{\gamma \in[0,1]} \frac{\int_{0}^{\gamma} x U_{(j)} d x+\int_{\gamma}^{1} x L_{(j)} d x}{\int_{0}^{\gamma} L_{(j)} d x+\int_{\gamma}^{1} U_{(j)} d x} \\
L_{(j)}=\min _{i} L_{(i j)} \\
U_{(j)}=\max _{i} U_{(i j)}
\end{gathered}
$$

Step 2.3. Then we obtain the centroid value of $\omega_{j}$ :

$$
C\left(\omega_{j}\right)=\frac{\bar{C}\left(\omega_{j}\right)+\underline{C}\left(\omega_{j}\right)}{2}
$$

Step 2.4. Then the normalized weights of criteria $C_{j}(j=1,2, \ldots, n)$ can be calculated by the following formula:

$$
\omega_{j}=\frac{C\left(\omega_{j}\right)}{\sum_{j=1}^{m} C\left(\omega_{j}\right)}
$$

where $\omega_{j}$ is the weight value of the criteria $C_{j}$. 


\section{Fuzzy VIKOR}

The VIKOR method is one of the most popular MADM techniques, which has been increasingly applied by researchers for solving problems in the real world such as (1) manufacturing, (2) performance evaluation, (3) supply chain, and (4) sustainability and renewable energy [60]. In this paper, fuzzy VIKOR was used to evaluate the alternatives. Taking the intuitionistic fuzzy number as an example, the calculation steps of the fuzzy VIKOR are as follows:

Step 3.1. Construct the fuzzy performance matrix $D$. It is necessary to evaluate alternatives with respect to criteria using triangular fuzzy numbers:

$$
D=\begin{gathered}
M_{1} \\
N_{1} \\
N_{2} \\
\vdots \\
N_{n}
\end{gathered} \quad\left[\begin{array}{cccc}
\widetilde{a}_{11} & \widetilde{a}_{12} & \cdots & M_{m} \\
\widetilde{a}_{21} & \widetilde{a}_{22} & \cdots & \widetilde{a}_{2 m} \\
\vdots & \vdots & \vdots & \vdots \\
\widetilde{a}_{n 1} & \widetilde{a}_{n 2} & \widetilde{a}_{n 3} & \widetilde{a}_{n m}
\end{array}\right]
$$

where $N_{i}$ denotes the alternatives, i.e., design partners. $M_{j}$ represents the criterion $j(j=1,2, \ldots, n)$; $\widetilde{a}_{i j}=\left(l_{i j}, u_{i j}\right)$ indicates the fuzzy performance rating of alternative $N_{n}$ with respect to $M_{j}$.

Step 3.2. Calculate the score function $S\left(\widetilde{a}_{i j}\right)$ according to Equation (2) and normalize it by the following formula:

$$
S^{\prime}\left(\widetilde{a}_{i j}\right)=\frac{S\left(\widetilde{a}_{i j}\right)-\min _{i} S\left(\widetilde{a}_{i j}\right)}{\max _{i} S\left(\widetilde{a}_{i j}\right)-\min _{i} S\left(\widetilde{a}_{i j}\right)}
$$

Step 3.3. Compute the value $S_{i}$, which represents the normalized fuzzy difference, i.e., the maximum group utility, and $R_{i}$, which represents the maximum fuzzy difference, i.e., the minimum individual regret, by the equations:

$$
\begin{aligned}
S_{i} & =\sum_{j=1}^{m} w_{j} S^{\prime}\left(\widetilde{a}_{i j}\right) \\
R_{i} & =\max _{j} w_{j} S^{\prime}\left(\widetilde{a}_{i j}\right)
\end{aligned}
$$

Step 3.4. Calculate the value $Q_{i}$, i.e., the overall distance of the alternative from the ideal solution, by the equation:

$$
Q_{i}=v \frac{S_{i}-\min _{i} S_{i}}{\max _{i} S_{i}-\min _{i} S_{i}}+(1-v) \frac{R_{i}-\min _{i} R_{i}}{\max _{i} R_{i}-\min _{i} R_{i}}
$$

The value $v$ is introduced as a weight for the strategy of "the majority of criteria" (or "the maximum group utility"), whereas $1-v$ is the weight of the individual regret. This paper supposes $v=0.5$ to pursue the maximization group utility and the minimization of individual regret.

\section{Case Study}

New energy vehicles are also green products, and refer to the use of non-conventional vehicle fuels as a power source (or the use of conventional fuels with a new vehicle power device). In recent years, against the dual background of a high oil price and a low carbon economy, new energy vehicles are more popular. To demonstrate the effectiveness of the proposed method, a field investigation of a new energy vehicle manufacturer was conducted. Enterprise $T$ is a new energy automobile manufacturer in China. By seizing market share and improving core competitiveness, and in accordance with the concept of green and sustainable development, Enterprise $\mathrm{T}$ aspires to design more creative and technical clean energy automobile products. Therefore, it is necessary to select appropriate collaborative design partners. Through the investigation, we found out that there were about 20 evaluation indices for partner selection, which are regional reputation (D1), financial strength 
(D2), cost (D3), punctual completion rate (D4), technical ability (D5), service quality (D6), capacity of communication and feedback (D7), cooperative degree (D8), scientific research advantage (D9), emission of pollution gas (D10), integrity degree (D11), influence degree of design (D12), service satisfaction (D13), long-term cooperation potential (D14), green enterprise image (D15), risk-taking capacity (D16), information transmission capacity (D17), green cultural compatibility (D18), proportion of clean energy use (D19), and market share (D20). To reduce the workload of the evaluation process, we first selected the main indices. However, the 20 indices are not independent of each other, e.g., quality and cost are mutually affected. There is also a certain relationship between the advantages of scientific research and technical ability, as perhaps greater advantages bring more technical ability. Therefore, we had to find out the interaction between these indices, which were solved in the first stage of the proposed method. The next challenge was how to acquire the weights of the selected evaluation indices. Thus, in the second stage, a fuzzy KMA algorithm was used to avoid the shortcomings of subjective weights, and then a fuzzy VIKOR method was applied to select the suitable design partner. The procedure of the proposed two-stage dynamic hybrid MADM is shown in detail as follows:

\subsection{The First Stage}

In the first stage, we used fuzzy DEMATEL to obtain the main indices for the selection of design partners.

Step 1. Experts use fuzzy language \{No influence, Low influence, Medium influence, High influence, Very high influence\} from the influence between these indices to make a qualitative evaluation. Then, the triangular fuzzy evaluation matrix is obtained according to Table 2, and the evaluation matrix is shown in Tables 3 and 4.

Step 2. From Equation (7), the triangular fuzzy number is singularized, and the effect of the index on itself is not taken into account, and the single value evaluation matrix is obtained (Table 5).

Step 3. According to Equations (8)-(12), the total influence relation matrix (Table 6) between the indices and the DEMATEL value of each index are obtained (Table 7).

Step 4. Combined with expert advice, set the initial value $Y_{c}{ }^{0}=3.0, Y_{d}{ }^{0}=0.5$. Get the main impact index set $M=\{\mathrm{D} 2, \mathrm{D} 6, \mathrm{D} 8, \mathrm{D} 11, \mathrm{D} 14, \mathrm{D} 15\}$. The specific meanings of these indices are as follows:

D2 (Financial strength $M_{1}$ ): Mainly uses registered capital and liquidity to measure, reflecting the design of the main economic strength. It determines the share of the new energy automobile market.

D6 (Service quality $M_{2}$ ): Mainly expressed as the pass rate of the products or services provided by the design partner. This will greatly affect the sales of new energy automobiles.

D8 (Collaborative degree $M_{3}$ ): Determine the collaborative strength, collaborative duration, collaborative satisfaction together. Collaborative strength refers to the number of cooperative projects, collaborative duration refers to the time span of cooperative projects, and collaborative satisfaction refers to the cooperation to bring a lot of satisfaction.

D11 (Integrity degree $M_{4}$ ): This is an important reference index for collaborative design. It is expressed as the credibility of the design unit.

D14 (Long-term cooperation potential $M_{5}$ ): This is used to measure the potential of a design unit for long-term cooperation. In other words, it can measure the sustainability of a design partner.

D15 (Green enterprise image $M_{6}$ ): The level of willingness to cooperate has seriously affected the enthusiasm of collaboration and cooperation.

Step 5. Based on these key indices and considering the experts' opinions, screen out the five design partners, recorded as the set $N=\left\{N_{1}, N_{2}, N_{3}, N_{4}, N_{5}\right\}$. 
Table 3. Fuzzy evaluation matrix.

\begin{tabular}{|c|c|c|c|c|c|c|c|c|c|c|}
\hline & D1 & D2 & D3 & D4 & D5 & D6 & D7 & D8 & D9 & D10 \\
\hline D1 & $*$ & $(0,0.25,0.50)$ & $(0,0.25,0.50)$ & $(0,0.25,0.50)$ & $(0.50,0.75,1)$ & $(0,0,0.25)$ & $(0,0.25,0.50)$ & $(0,0.25,0.50)$ & $(0,0.25,0.50)$ & $(0,0.25,0.50)$ \\
\hline D2 & $(0,0.25,0.50)$ & $*$ & $(0,0,0.25)$ & $(0,0.25,0.50)$ & $(0,0,0.25)$ & $(0,0.25,0.50)$ & $(0,0,0.25)$ & $(0,0,0.25)$ & $(0.50,0.75,1)$ & $(0.50,0.75,1)$ \\
\hline D3 & $(0,0.25,0.50)$ & $(0.50,0.75,1)$ & $*$ & $(0,0.25,0.50)$ & $(0,0.25,0.50)$ & $(0.50,0.75,1)$ & $(0,0.25,0.50)$ & $(0,0.25,0.50)$ & $(0,0.25,0.50)$ & $(0,0.25,0.50)$ \\
\hline D4 & $(0,0.25,0.50)$ & $(0,0,0.25)$ & $(0,0,0.25)$ & $*$ & $(0,0.25,0.50)$ & $(0,0.25,0.50)$ & $(0,0.25,0.50)$ & $(0,0.25,0.50)$ & $(0,0.25,0.50)$ & $(0,0.25,0.50)$ \\
\hline D5 & $(0,0.25,0.50)$ & $(0,0,0.25)$ & $(0,0.25,0.50)$ & $(0,0.25,0.50)$ & * & $(0,0.25,0.50)$ & $(0,0.25,0.50)$ & $(0,0.25,0.50)$ & $(0,0.25,0.50)$ & $(0,0.25,0.50)$ \\
\hline D6 & $(0,0.25,0.50)$ & $(0,0,0.25)$ & $(0.50,0.75,1)$ & $(0,0.25,0.50)$ & $(0.75,1,1)$ & $*$ & $(0,0.25,0.50)$ & $(0,0.25,0.50)$ & $(0.75,1,1)$ & $(0,0.25,0.50)$ \\
\hline D7 & $(0,0,0.25)$ & $(0,0,0.25)$ & $(0,0.25,0.50)$ & $(0,0.25,0.50)$ & $(0,0.25,0.50)$ & $(0,0,0.25)$ & * & $(0.50,0.75,1)$ & $(0.50,0.75,1)$ & $(0,0.25,0.50)$ \\
\hline D8 & $(0,0.25,0.50)$ & $(0,0.25,0.50)$ & $(0,0.25,0.50)$ & $(0.50,0.75,1)$ & $(0.50,0.75,1)$ & $(0.50,0.75,1)$ & $(0.75,1,1)$ & * & $(0.75,1,1)$ & $(0.75,1,1)$ \\
\hline D9 & $(0,0.25,0.50)$ & $(0,0.25,0.50)$ & $(0,0.25,0.50)$ & $(0,0.25,0.50)$ & $(0,0.25,0.50)$ & $(0.75,1,1)$ & $(0.50,0.75,1)$ & $(0.50,0.75,1)$ & * & $(0,0.25,0.50)$ \\
\hline D10 & $(0,0.25,0.50)$ & $(0,0,0.25)$ & $(0.50,0.75,1)$ & $(0.50,0.75,1)$ & $(0,0.25,0.50)$ & $(0.50,0.75,1)$ & $(0,0.25,0.50)$ & $(0.50,0.75,1)$ & $(0.50,0.75,1)$ & * \\
\hline D11 & $(0.75,1,1)$ & $(0,0,0.25)$ & $(0,0,0.25)$ & $(0.75,1,1)$ & $(0,0.25,0.50)$ & $(0,0.25,0.50)$ & $(0,0.25,0.50)$ & $(0,0.25,0.50)$ & $(0,0.25,0.50)$ & $(0.50,0.75,1)$ \\
\hline D12 & $(0.75,1,1)$ & $(0,0,0.25)$ & $(0,0.25,0.50)$ & $(0,0.25,0.50)$ & $(0.50,0.75,1)$ & $(0.50,0.75,1)$ & $(0,0.25,0.50)$ & $(0,0.25,0.50)$ & $(0,0.25,0.50)$ & $(0,0.25,0.50)$ \\
\hline D13 & $(0.75,1,1)$ & $(0,0,0.25)$ & $(0,0.25,0.50)$ & $(0,0.25,0.50)$ & $(0.50,0.75,1)$ & $(0,0,0.25)$ & $(0,0.25,0.50)$ & $(0.75,1,1)$ & $(0,0.25,0.50)$ & $(0,0.25,0.50)$ \\
\hline D14 & $(0,0,0.25)$ & $(0,0,0.25)$ & $(0,0.25,0.50)$ & $(0,0.25,0.50)$ & $(0,0.25,0.50)$ & $(0,0.25,0.50)$ & $(0,0.25,0.50)$ & $(0,0.25,0.50)$ & $(0,0.25,0.50)$ & $(0,0.25,0.50)$ \\
\hline D15 & $(0,0,0.25)$ & $(0,0,0.25)$ & $(0,0.25,0.50)$ & $(0,0.25,0.50)$ & $(0,0.25,0.50)$ & $(0,0.25,0.50)$ & $(0,0.25,0.50)$ & $(0,0.25,0.50)$ & $(0,0.25,0.50)$ & $(0,0.25,0.50)$ \\
\hline D16 & $(0,0,0.25)$ & $(0,0,0.25)$ & $(0,0.25,0.50)$ & $(0,0.25,0.50)$ & $(0,0.25,0.50)$ & $(0,0,0.25)$ & $(0,0.25,0.50)$ & $(0,0.25,0.50)$ & $(0,0.25,0.50)$ & $(0,0.25,0.50)$ \\
\hline D17 & $(0,0.25,0.50)$ & $(0,0,0.25)$ & $(0,0.25,0.50)$ & $(0,0.25,0.50)$ & $(0,0.25,0.50)$ & $(0,0.25,0.50)$ & $(0.50,0.75,1)$ & $(0.50,0.75,1)$ & $(0,0.25,0.50)$ & $(0,0.25,0.50)$ \\
\hline D18 & $(0,0,0.25)$ & $(0,0,0.25)$ & $(0,0.25,0.50)$ & $(0,0.25,0.50)$ & $(0,0.25,0.50)$ & $(0,0,0.25)$ & $(0.50,0.75,1)$ & $(0,0.25,0.50)$ & $(0,0.25,0.50)$ & $(0,0.25,0.50)$ \\
\hline D19 & $(0,0,0.25)$ & $(0,0,0.25)$ & $(0,0.25,0.50)$ & $(0,0.25,0.50)$ & $(0,0.25,0.50)$ & $(0,0,0.25)$ & $(0,0.25,0.50)$ & $(0,0.25,0.50)$ & $(0,0.25,0.50)$ & $(0.50,0.75,1)$ \\
\hline D20 & $(0.75,1,1)$ & $(0,0,0.25)$ & $(0.50,0.75,1)$ & $(0,0.25,0.50)$ & $(0,0.25,0.50)$ & $(0,0.25,0.50)$ & $(0,0.25,0.50)$ & $(0,0.25,0.50)$ & $(0,0.25,0.50)$ & $(0,0.25,0.50)$ \\
\hline
\end{tabular}

Note: "** Means no need to compare here. 
Table 4. Fuzzy evaluation matrix.

\begin{tabular}{|c|c|c|c|c|c|c|c|c|c|c|}
\hline & D11 & D12 & D13 & D14 & D15 & D16 & D17 & D18 & D19 & D20 \\
\hline D1 & $(0.50,0.75,1)$ & $(0.75,1,1)$ & $(0,0.25,0.50)$ & $(0.50,0.75,1)$ & $(0,0.25,0.50)$ & $(0,0.25,0.50)$ & $(0,0.25,0.50)$ & $(0,0.25,0.50)$ & $(0,0.25,0.50)$ & $(0.75,1,1)$ \\
\hline D2 & $(0,0.25,0.50)$ & $(0,0.25,0.50)$ & $(0,0.25,0.50)$ & $(0,0.25,0.50)$ & $(0,0.25,0.50)$ & $(0,0.25,0.50)$ & $(0,0.25,0.50)$ & $(0,0.25,0.50)$ & $(0,0.25,0.50)$ & $(0,0.25,0.50)$ \\
\hline D3 & $(0,0.25,0.50)$ & $(0,0.25,0.50)$ & $(0,0.25,0.50)$ & $(0.75,1,1)$ & $(0.75,1,1)$ & $(0,0.25,0.50)$ & $(0,0.25,0.50)$ & $(0,0.25,0.50)$ & $(0,0.25,0.50)$ & $(0.50,0.75,1)$ \\
\hline D4 & $(0.75,1,1)$ & $(0,0.25,0.50)$ & $(0,0.25,0.50)$ & $(0.75,1,1)$ & $(0.75,1,1)$ & $(0,0.25,0.50)$ & $(0,0.25,0.50)$ & $(0,0.25,0.50)$ & $(0,0.25,0.50)$ & $(0,0.25,0.50)$ \\
\hline D5 & $(0.25,0.50,0.75)$ & $(0,0,0.25)$ & $(0,0.25,0.50)$ & $(0.75,1,1)$ & $(0.75,1,1)$ & $(0.75,1,1)$ & $(0,0.25,0.50)$ & $(0,0.25,0.50)$ & $(0,0.25,0.50)$ & $(0.50,0.75,1)$ \\
\hline D6 & $(0,0.25,0.50)$ & $(0,0.25,0.50)$ & $(0,0.25,0.50)$ & $(0.75,1,1)$ & $(0.75,1,1)$ & $(0.75,1,1)$ & $(0,0.25,0.50)$ & $(0,0.25,0.50)$ & $(0.50,0.75,1)$ & $.25,0.50)$ \\
\hline D7 & $(0,0.25,0.50)$ & $(0,0.25,0.50)$ & $(0.50,0.75,1)$ & $(0.50,0.75,1)$ & $(0.75,1,1)$ & $(0.50,0.75,1)$ & $(0.75,1,1)$ & $5,0.50)$ & $.25,0.50)$ & $25,0.50)$ \\
\hline D8 & $(0,0.25,0.50)$ & $(0,0.25,0.50)$ & $(0.75,1,1)$ & $(0.75,1,1)$ & $(0.50,0.75,1)$ & $.25,0.50)$ & $, 0.50)$ & $5,0.50)$ & $0.25,($ & $0.50)$ \\
\hline D9 & $(0,0.25,0.50)$ & $(0,0.25,0.50)$ & $(0,0.25,0.50)$ & $(0,0.25,0.50)$ & $(0$, & 0) & $(0$, & $5,0.50)$ & $(0.50,0$ & $25,0.50)$ \\
\hline D10 & $(0,0.25,0.50)$ & $(0.25,0.50,0.75)$ & $(0.25,0.50,0.75)$ & $(0,0.25,0.50)$ & $(0,0.25,0.50)$ & $(0,0.25,0.50)$ & $(0,0.25,0.50)$ & $(0,0.25,0.50)$ & $(0,0.25,0.50)$ & $(0,0.25,0.50)$ \\
\hline D11 & $*$ & $(0,0.25,0.50)$ & $(0.50,0.75,1)$ & $(0.50,0.75,1)$ & $(0.50,0.75,1)$ & $(0.50,0.75,1)$ & $(0,0.25,0.50)$ & $(0.50,0.75,1)$ & $(0.50,0.75,1)$ & $(0,0.25,0.50)$ \\
\hline D12 & $(0,0.25,0.50)$ & * & $(0,0.25,0.50)$ & $(0,0.25,0.50)$ & $(0.50,0.75,1)$ & $(0.50,0.75,1)$ & $(0,0.25,0.50)$ & $(0,0.25,0.50)$ & $(0,0.25,0.50)$ & $(0.50,0.75,1)$ \\
\hline D13 & $(0.50,0.75,1)$ & $(0,0.25,0.50)$ & * & $(0,0.25,0.50)$ & $(0,0.25,0.50)$ & $(0,0.25,0.50)$ & $(0,0.25,0.50)$ & $(0,0.25,0.50)$ & $(0,0.25,0.50)$ & $(0,0.25,0.50)$ \\
\hline D14 & $(0,0.25,0.50)$ & $(0,0.25,0.50)$ & $(0,0.25,0.50)$ & * & $(0.50,0.75,1)$ & $(0.50,0.75,1)$ & $(0,0.25,0.50)$ & $(0,0.25,0.50)$ & $(0,0.25,0.50)$ & $(0,0.25,0.50)$ \\
\hline D15 & $(0,0.25,0.50)$ & $(0,0.25,0.50)$ & $(0,0.25,0.50)$ & $(0.50,0.75,1)$ & * & $(0.50,0.75,1)$ & $(0,0.25,0.50)$ & $(0,0.25,0.50)$ & $(0,0.25,0.50)$ & $(0,0.25,0.50)$ \\
\hline D16 & $(0,0.25,0.50)$ & $(0,0.25,0.50)$ & $(0,0.25,0.50)$ & $(0.75,1,1)$ & $(0,0.25,0.50)$ & $*$ & $(0,0.25,0.50)$ & $(0,0.25,0.50)$ & $(0,0.25,0.50)$ & $(0,0.25,0.50)$ \\
\hline D17 & $(0,0.25,0.50)$ & $(0.50,0.75,1)$ & $(0,0.25,0.50)$ & $(0,0.25,0.50)$ & $(0,0.25,0.50)$ & $(0.50,0.75,1)$ & $*$ & $(0.50,0.75,1)$ & $(0,0.25,0.50)$ & $(0.50,0.75,1)$ \\
\hline D18 & $(0,0.25,0.50)$ & $(0,0.25,0.50)$ & $(0,0.25,0.50)$ & $(0.50,0.75,1)$ & $(0.50,0.75,1)$ & $(0.50,0.75,1)$ & $(0,0.25,0.50)$ & * & $(0.50,0.75,1)$ & $(0,0.25,0.50)$ \\
\hline D19 & $(0,0.25,0.50)$ & $(0,0.25,0.50)$ & $(0,0.25,0.50)$ & $(0.75,1,1)$ & $(0.50,0.75,1)$ & $(0.75,1,1)$ & $(0,0.25,0.50)$ & $(0.50,0.7$ & * & $(0,0.25,0.50)$ \\
\hline D20 & $(0,0.25,0.50)$ & $(0,0.25,0.50)$ & $(0,0.25,0.50)$ & $(0,0.25,0.50)$ & $(0,0.25,0.50)$ & $(0,0.25,0.50)$ & $(0,0.25,0.50)$ & $(0,0.25,0.50)$ & $(0.50,0.75,1)$ & * \\
\hline
\end{tabular}

Note: "** Means no need to compare here. 
Table 5. The initial direct-relation matrix.

\begin{tabular}{|c|c|c|c|c|c|c|c|c|c|c|c|c|c|c|c|c|c|c|c|c|}
\hline & D1 & D2 & D3 & D4 & D5 & D6 & D7 & D8 & D9 & D10 & D11 & D12 & D13 & D14 & D15 & D16 & D17 & D18 & D19 & D20 \\
\hline D1 & 0 & 250 & 250 & 250 & 750 & 42 & 250 & 0.250 & 0.250 & 0.250 & 0.750 & 0.958 & 0.250 & .750 & 250 & 250 & 0.250 & 0.250 & 0.250 & 0.958 \\
\hline D2 & 0.250 & 0 & 0.042 & 0.250 & 0.042 & 0250 & 0042 & 042 & & & & & & .250 & & & & & 0.250 & 0.250 \\
\hline D3 & 0.250 & 0.750 & 0 & 250 & 250 & 0.750 & 50 & & 0.250 & & & & & 58 & & 50 & 50 & 50 & 250 & 750 \\
\hline D4 & 0.250 & 0.042 & 042 & 0 & 0.250 & 0.250 & 0.250 & & 0.250 & 0.250 & & & & 58 & & 50 & 50 & 50 & 250 & 250 \\
\hline D5 & 0.250 & 0. & 0 & 25 & 0 & 0.250 & 0.2 & & & 0. & & & & 8 & & & & & 0.250 & 750 \\
\hline D6 & 0.250 & 0 & ) & 0. & 0.05 & 0 & 0.250 & 0 & $0 . S$ & 0 & 0 . & 0. & 0 & .958 & 8 & 58 & 0 & 0 & .750 & .250 \\
\hline D7 & 0.042 & 0.042 & 50 & 0.250 & 0.250 & 0.042 & 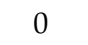 & 0.750 & 0.750 & 0 . & 0 . & & 50 & 0.750 & 50 & 50 & & 0 & .250 & 250 \\
\hline D8 & 0.250 & 0 & 50 & 0.750 & 0.750 & 0.750 & 0.958 & 0 & 0.958 & 0.958 & 0 . & & 8 & 0.958 & 88 & 50 & 0 & 50 & .250 & 250 \\
\hline D9 & 0.250 & 0 & 50 & 0.250 & 02 & 0.5 & 0.7 & .750 & 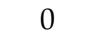 & 0.250 & 0.2 & & 0 & 0.250 & 50 & 50 & 0 & 0 & 0.750 & 0.250 \\
\hline D10 & 0.250 & 0.042 & 750 & 0.750 & 0.250 & 0.750 & 0.250 & 0.750 & 0.750 & 0 & 0.250 & 0.500 & 0.500 & 0.250 & 0.250 & 0.250 & 0.250 & 0.250 & 0.250 & 0.250 \\
\hline D11 & 0.958 & 0.042 & 0.042 & 0.958 & 0.250 & 0.250 & 0.250 & 0.250 & 0.250 & 0.750 & 0 & 0.250 & 0.750 & 0.750 & 0.750 & 0.750 & 0.250 & 0.750 & 0.750 & 0.250 \\
\hline D12 & 0.958 & 0.042 & 0.250 & 0.250 & 0.750 & 0.750 & 0.250 & 0.250 & 0.250 & 0.250 & 0.250 & 0 & 0.250 & 0.250 & 0.750 & 0.750 & 0.250 & 0.250 & 0.250 & 0.750 \\
\hline D13 & 0.958 & 0.042 & 0.250 & 0.250 & 0.750 & 0.042 & 0.250 & 0.958 & 0.250 & 0.250 & 0.750 & 0.250 & 0 & 0.250 & 0.250 & 0.250 & 0.250 & 0.250 & 0.250 & 0.250 \\
\hline D14 & 0.042 & 0.042 & 0.250 & 0.250 & 0.250 & 0.250 & 0.250 & 0.250 & 0.250 & 0.250 & 0.250 & 0.250 & 0.250 & 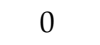 & 0.750 & 0.750 & 0.250 & 0.250 & 0.250 & 0.250 \\
\hline D15 & 0.042 & 0.042 & 0.250 & 0.250 & 0.250 & 0.250 & 0.250 & 0.250 & 0.250 & 0.250 & 0.250 & 0.250 & 0.250 & 0.750 & 0 & 0.750 & 0.250 & 0.250 & 0.250 & 0.250 \\
\hline D16 & 0.042 & 0.042 & 0.250 & 0.250 & 0.025 & 0.042 & 0.250 & 0.250 & 0.250 & 0.250 & 0.250 & 0.250 & 0.250 & 0.958 & 0.250 & 0 & 0.250 & 0.250 & 0.250 & 0.250 \\
\hline D17 & 0.25 & 0.042 & 50 & 0.250 & 0.250 & 0250 & 0.750 & .750 & 0.250 & 0.250 & 0.250 & 0.750 & 0.250 & 0.250 & 0.250 & 0.750 & 0 & 0.750 & .250 & 0.750 \\
\hline 118 & 0.042 & 44 & 50 & 50 & 250 & 0.042 & 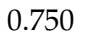 & 50 & 0250 & 0.250 & 0250 & 0 & 0 & 0.750 & 0.750 & 0.750 & 0.250 & 0 & 0.750 & 0.250 \\
\hline D19 & 0.042 & 0.042 & 250 & 0.250 & 0.250 & 0.0 & 0.250 & 250 & 0.250 & 0.750 & 0.250 & 0 & 50 & 0.958 & 0.958 & 0.958 & 0.250 & .750 & 0 & 0.250 \\
\hline D20 & 0.958 & 0.042 & 0.750 & 0.250 & 0.250 & 0.250 & 0.250 & 0.250 & 0.250 & 0.250 & 0.250 & 0.250 & 0.250 & 0.250 & 0.250 & 0.250 & 0.250 & 0.250 & 0.750 & 0 \\
\hline
\end{tabular}


Table 6. Total influence relation matrix.

\begin{tabular}{|c|c|c|c|c|c|c|c|c|c|c|c|c|c|c|c|c|c|c|c|c|}
\hline & D1 & 2 & 3 & 4 & D5 & D6 & D7 & 88 & 99 & D10 & D11 & 12 & 13 & 14 & D15 & D16 & D17 & $\mathrm{D} 18$ & D19 & D20 \\
\hline D1 & 043 & & & & 102 & & & 01 & & $0 \cap 0$ & ค 000 & (11 11 & 0.060 & & 0088 & 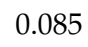 & - & 58 & 4 & 121 \\
\hline D2 & & & & & & & & & & & & & & & & & & & & \\
\hline D3 & & & & & & & & & & & & & & & & & & & & 100 \\
\hline D4 & & & & & & & & & & & & & & & & & & & & .055 \\
\hline D5 & & & & & & & & & & & & & & & & & & & & .097 \\
\hline D6 & & & & & & & & & & & & & & & & & & & & 071 \\
\hline D7 & & & & & & & & & & & & & & & & & & & & 064 \\
\hline D8 & & & & & & & & & & & & & & & & & & & & 577 \\
\hline D9 & & & & & & & & & & & & & & & & & & & & 60 \\
\hline D10 & & & & & & & & & & & & & & & & & & & & 065 \\
\hline D1 & & & & & & & & & & & & & & & & & & & & 071 \\
\hline & & & & & & & & & & & & & & & & & & & & 07 \\
\hline & & & & & & & & & & & & & & & & & & & & 064 \\
\hline D1 & & & & & & & & & & & & & & & & & & & & 049 \\
\hline D1 & & & & & & & & & & & & & & & & & & & & .049 \\
\hline D16 & & & & & & & & & & & & & & & & & & & 47 & 0.047 \\
\hline r & & & & & & & & & & & & & & & & & & & & 0.103 \\
\hline & & & & & & & & & & & & & & & & & & & & 0.055 \\
\hline D & & & & & & & & & & & & & & & & & & & & 0.056 \\
\hline D20 & 0.106 & 0.016 & 0.089 & 052 & 0.058 & 0.051 & 0.054 & 0.056 & 56 & 0.055 & 0.055 & 0.053 & 0.053 & 0.085 & 0.078 & 0.073 & 0.048 & 0.053 & 0.095 & 0.041 \\
\hline
\end{tabular}


Table 7. The result of DEMATEL for each index.

\begin{tabular}{cccccccccc}
\hline & $\boldsymbol{D}$ & $\boldsymbol{R}$ & $\boldsymbol{D}+\boldsymbol{R}$ & $\boldsymbol{D}-\boldsymbol{R}$ & & $\boldsymbol{D}$ & $\boldsymbol{R}$ & $\boldsymbol{D}+\boldsymbol{R}$ & $\boldsymbol{D}-\boldsymbol{R}$ \\
\hline D1 & 1.437 & 1.173 & 2.610 & 0264 & $\mathrm{D} 11$ & 1.739 & 1.284 & 3.023 & 0.455 \\
D2 & 0.954 & 0.400 & 1.354 & 0.554 & $\mathrm{D} 12$ & 1.485 & 1.142 & 2.627 & 0.343 \\
D3 & 1.434 & 1.107 & 2.541 & 0.327 & $\mathrm{D} 13$ & 1.365 & 1.297 & 2.662 & 0.068 \\
D4 & 1.241 & 1.248 & 2.489 & -0.007 & $\mathrm{D} 14$ & 1.014 & 2.369 & 3.383 & -1.355 \\
D5 & 1.338 & 1.392 & 2.730 & -0.054 & $\mathrm{D} 15$ & 1.014 & 2.164 & 3.178 & -1.150 \\
D6 & 1.694 & 1.187 & 2.881 & 0.507 & $\mathrm{D} 16$ & 0.925 & 2.029 & 2.954 & -1.104 \\
D7 & 1.502 & 1.311 & 2.813 & 0.191 & $\mathrm{D} 17$ & 1.474 & 1.061 & 2.535 & 0.413 \\
D8 & 2.005 & 1.402 & 3.407 & 0.603 & $\mathrm{D} 18$ & 1.243 & 1.200 & 2.443 & 0.043 \\
D9 & 1.396 & 1.432 & 2.828 & -0.036 & $\mathrm{D} 19$ & 1.306 & 1.391 & 2.697 & -0.085 \\
D10 & 1.507 & 1.310 & 2.817 & 0.197 & $\mathrm{D} 20$ & 1.225 & 1.402 & 2.627 & -0.177 \\
\hline
\end{tabular}

\subsection{The Second Stage}

In the second stage, we combined fuzzy KMA and fuzzy VIKOR as well as dynamic integration operators to complete the decision-making process, i.e., to select the most suitable design partner in the PCD. As a matter of fact, it is a complex task involving different phases (Figure 2), and the design phases can be divided into three parts: the conceptual design phase, the detailed design phase, and the trial production feedback phase. In addition, there are great differences between each phase for different tasks and demands. For example, in the conceptual design phase, the financial strength and service quality may be taken into account in the first place; however, for the detailed design phase, the collaborative degree is more important. As for the trial production feedback phase, the potential for long-term cooperation, integrity degree, and willingness to cooperate stands out. Therefore, it is a dynamic evaluation process. Taking the full design process into account, we invited three experts to give their opinions for each different design phases.

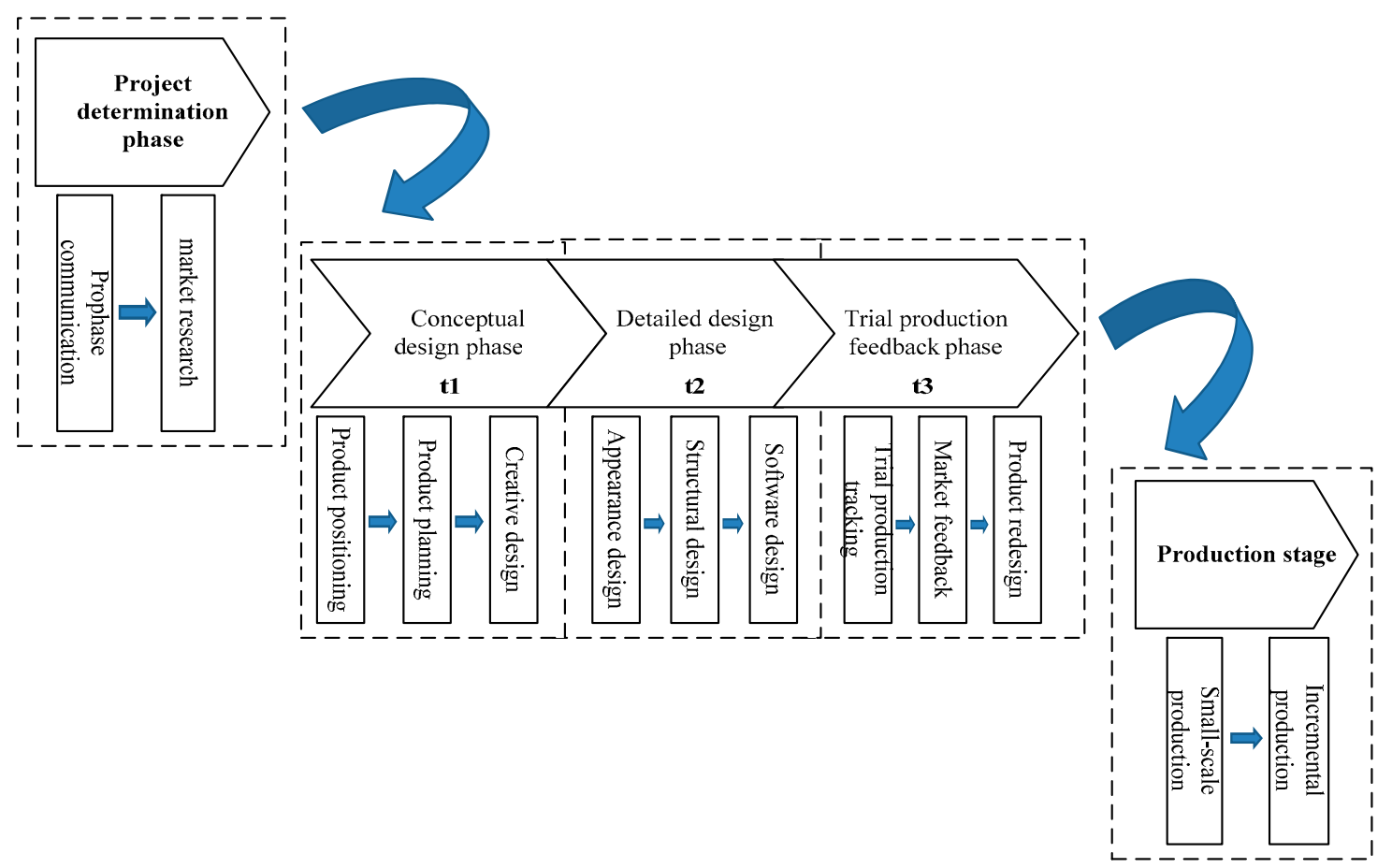

Figure 2. The different phases of product design.

Experts 1, 2, and 3 gave their opinions on design partners $N_{i}(I=1,2,3,4,5)$ at each different design phase $t_{k}(k=1,2,3)$, respectively. The resulting evaluation matrices are shown in Tables 8-10. 
The period weight was set to $w_{1}=(0.3,0.4,0.3)$ and the weight of the expert is given as $w_{2}=(0.2429$, $0.5142,0.2429)$ according to the normal distribution assignment method of position weights [61].

Table 8. The first experts' multi-stage evaluation value.

\begin{tabular}{cccccccc}
\hline \multirow{2}{*}{ Design Stage } & Design Partner & \multicolumn{7}{c}{ The Evaluation Index } \\
\cline { 2 - 8 } & & $\boldsymbol{M}_{\mathbf{1}}$ & $\boldsymbol{M}_{\mathbf{2}}$ & $\boldsymbol{M}_{\mathbf{3}}$ & $\boldsymbol{M}_{\mathbf{4}}$ & $\boldsymbol{M}_{\mathbf{5}}$ & $\boldsymbol{M}_{\mathbf{6}}$ \\
\hline \multirow{4}{*}{$t_{1}$} & $N_{1}$ & $(0.8,0.1)$ & $(0.6,0.2)$ & $(0.5,0.2)$ & $(0.7,0.3)$ & $(0.5,0.2)$ & $(0.7,0.1)$ \\
& $N_{2}$ & $(0.6,0.2)$ & $(0.4,0.5)$ & $(0.6,0.3)$ & $(0.6,0.3)$ & $(0.7,0.1)$ & $(0.2,0.7)$ \\
& $N_{3}$ & $(0.7,0.2)$ & $(0.3,0.5)$ & $(0.4,0.3)$ & $(0.7,0.4)$ & $(0.5,0.1)$ & $(0.3,0.5)$ \\
& $N_{4}$ & $(0.5,0.3)$ & $(0.2,0.4)$ & $(0.2,0.4)$ & $(0.6,0.3)$ & $(0.4,0.5)$ & $(0.3,0.6)$ \\
& $N_{5}$ & $(0.7,0.3)$ & $(0.5,0.3)$ & $(0.5,0.1)$ & $(0.5,0.2)$ & $(0.4,0.4)$ & $(0.4,0.5)$ \\
\hline \multirow{3}{*}{$t_{2}$} & $N_{1}$ & $(0.7,0.1)$ & $(0.6,0.2)$ & $(0.5,0.2)$ & $(0.7,0.2)$ & $(0.6,0.1)$ & $(0.7,0.2)$ \\
& $N_{2}$ & $(0.6,0.2)$ & $(0.4,0.5)$ & $(0.4,0.3)$ & $(0.6,0.3)$ & $(0.7,0.1)$ & $(0.2,0.8)$ \\
& $N_{3}$ & $(0.7,0.3)$ & $(0.3,0.5)$ & $(0.2,0.3)$ & $(0.7,0.4)$ & $(0.6,0.3)$ & $(0.4,0.5)$ \\
& $N_{4}$ & $(0.5,0.4)$ & $(0.2,0.4)$ & $(0.2,0.4)$ & $(0.6,0.3)$ & $(0.2,0.8)$ & $(0.4,0.6)$ \\
& $N_{5}$ & $(0.8,0.2)$ & $(0.5,0.3)$ & $(0.5,0.1)$ & $(0.5,0.2)$ & $(0.4,0.5)$ & $(0.5,0.4)$ \\
\hline & $N_{1}$ & $(0.8,0.1)$ & $(0.6,0.2)$ & $(0.6,0.2)$ & $(0.7,0.1)$ & $(0.6,0.3)$ & $(0.8,0.2)$ \\
$t_{3}$ & $N_{2}$ & $(0.6,0.2)$ & $(0.3,0.6)$ & $(0.4,0.3)$ & $(0.6,0.3)$ & $(0.7,0.3)$ & $(0.2,0.6)$ \\
& $N_{3}$ & $(0.7,0.3)$ & $(0.4,0.5)$ & $(0.4,0.3)$ & $(0.7,0.4)$ & $(0.6,0.3)$ & $(0.4,0.5)$ \\
& $N_{4}$ & $(0.5,0.4)$ & $(0.1,0.8)$ & $(0.2,0.4)$ & $(0.6,0.3)$ & $(0.2,0.8)$ & $(0.3,0.5)$ \\
& $N_{5}$ & $(0.8,0.2)$ & $(0.6,0.3)$ & $(0.5,0.3)$ & $(0.6,0.2)$ & $(0.4,0.4)$ & $(0.6,0.3)$ \\
\hline
\end{tabular}

Table 9. The second experts' multi-stage evaluation value.

\begin{tabular}{cccccccc}
\hline \multirow{2}{*}{ Design Stage } & \multirow{6}{*}{ Design Partner } & \multicolumn{7}{c}{ The Evaluation Index } \\
\cline { 2 - 8 } & & $\boldsymbol{M}_{\mathbf{1}}$ & $\boldsymbol{M}_{\mathbf{2}}$ & $\boldsymbol{M}_{\mathbf{3}}$ & $\boldsymbol{M}_{\mathbf{4}}$ & $\boldsymbol{M}_{\mathbf{5}}$ & $\boldsymbol{M}_{\mathbf{6}}$ \\
\hline \multirow{4}{*}{$t_{1}$} & $N_{1}$ & $(0.8,0.1)$ & $(0.8,0.2)$ & $(0.7,0.2)$ & $(0.7,0.3)$ & $(0.6,0.2)$ & $(0.8,0.1)$ \\
& $N_{2}$ & $(0.5,0.3)$ & $(0.5,0.4)$ & $(0.6,0.2)$ & $(0.6,0.3)$ & $(0.7,0.1)$ & $(0.4,0.5)$ \\
& $N_{3}$ & $(0.7,0.1)$ & $(0.3,0.5)$ & $(0.4,0.3)$ & $(0.7,0.2)$ & $(0.5,0.1)$ & $(0.4,0.4)$ \\
& $N_{4}$ & $(0.5,0.3)$ & $(0.3,0.4)$ & $(0.2,0.4)$ & $(0.6,0.3)$ & $(0.4,0.5)$ & $(0.5,0.1)$ \\
& $N_{5}$ & $(0.7,0.2)$ & $(0.4,0.3)$ & $(0.6,0.1)$ & $(0.5,0.2)$ & $(0.4,0.4)$ & $(0.4,0.5)$ \\
\hline \multirow{4}{*}{$t_{2}$} & $N_{1}$ & $(0.9,0.1)$ & $(0.7,0.2)$ & $(0.8,0.2)$ & $(0.7,0.2)$ & $(0.6,0.2)$ & $(0.8,0.2)$ \\
& $N_{2}$ & $(0.6,0.2)$ & $(0.4,0.4)$ & $(0.7,0.2)$ & $(0.6,0.2)$ & $(0.4,0.1)$ & $(0.4,0.3)$ \\
& $N_{3}$ & $(0.7,0.3)$ & $(0.5,0.3)$ & $(0.2,0.3)$ & $(0.7,0.1)$ & $(0.6,0.3)$ & $(0.4,0.3)$ \\
& $N_{4}$ & $(0.5,0.2)$ & $(0.2,0.4)$ & $(0.2,0.3)$ & $(0.6,0.3)$ & $(0.2,0.4)$ & $(0.4,0.3)$ \\
& $N_{5}$ & $(0.8,0.1)$ & $(0.5,0.3)$ & $(0.5,0.3)$ & $(0.5,0.2)$ & $(0.4,0.5)$ & $(0.5,0.4)$ \\
\hline \multirow{4}{*}{$t_{3}$} & $N_{1}$ & $(0.8,0.1)$ & $(0.9,0.1)$ & $(0.7,0.2)$ & $(0.8,0.1)$ & $(0.6,0.3)$ & $(0.8,0.2)$ \\
& $N_{2}$ & $(0.6,0.2)$ & $(0.3,0.6)$ & $(0.4,0.3)$ & $(0.6,0.3)$ & $(0.7,0.2)$ & $(0.2,0.5)$ \\
& $N_{3}$ & $(0.6,0.3)$ & $(0.4,0.2)$ & $(0.4,0.3)$ & $(0.5,0.4)$ & $(0.6,0.3)$ & $(0.4,0.5)$ \\
& $N_{4}$ & $(0.5,0.4)$ & $(0.1,0.6)$ & $(0.2,0.4)$ & $(0.6,0.3)$ & $(0.2,0.3)$ & $(0.3,0.5)$ \\
& $N_{5}$ & $(0.7,0.2)$ & $(0.6,0.2)$ & $(0.6,0.3)$ & $(0.7,0.2)$ & $(0.4,0.2)$ & $(0.7,0.3)$ \\
\hline
\end{tabular}

Table 10. The third experts' multi-stage evaluation value.

\begin{tabular}{cccccccc}
\hline \multirow{2}{*}{ Design Stage } & Design Partner & \multicolumn{7}{c}{ The Evaluation Index } \\
\cline { 2 - 8 } & & $\boldsymbol{M}_{\mathbf{1}}$ & $\boldsymbol{M}_{\mathbf{2}}$ & $\boldsymbol{M}_{\mathbf{3}}$ & $\boldsymbol{M}_{\mathbf{4}}$ & $\boldsymbol{M}_{\mathbf{5}}$ & $\boldsymbol{M}_{\mathbf{6}}$ \\
\hline & $N_{1}$ & $(0.6,0.1)$ & $(0.7,0.1)$ & $(0.7,0.2)$ & $(0.7,0.3)$ & $(0.8,0.2)$ & $(0.9,0.1)$ \\
$N_{2}$ & $(0.6,0.3)$ & $(0.4,0.4)$ & $(0.6,0.2)$ & $(0.6,0.3)$ & $(0.7,0.1)$ & $(0.4,0.3)$ \\
$t_{1}$ & $N_{3}$ & $(0.8,0.1)$ & $(0.3,0.5)$ & $(0.4,0.3)$ & $(0.7,0.2)$ & $(0.5,0.1)$ & $(0.4,0.5)$ \\
& $N_{4}$ & $(0.5,0.4)$ & $(0.3,0.4)$ & $(0.2,0.6)$ & $(0.6,0.3)$ & $(0.4,0.5)$ & $(0.5,0.4)$ \\
& $N_{5}$ & $(0.8,0.2)$ & $(0.5,0.2)$ & $(0.7,0.2)$ & $(0.6,0.2)$ & $(0.4,0.3)$ & $(0.4,0.4)$ \\
\hline & $N_{1}$ & $(0.8,0.1)$ & $(0.7,0.2)$ & $(0.8,0.2)$ & $(0.7,0.2)$ & $(0.6,0.2)$ & $(0.8,0.1)$ \\
& $N_{2}$ & $(0.6,0.2)$ & $(0.4,0.4)$ & $(0.7,0.2)$ & $(0.6,0.2)$ & $(0.4,0.1)$ & $(0.4,0.3)$ \\
$t_{2}$ & $N_{3}$ & $(0.7,0.2)$ & $(0.5,0.2)$ & $(0.5,0.4)$ & $(0.7,0.2)$ & $(0.6,0.3)$ & $(0.4,0.3)$ \\
& $N_{4}$ & $(0.5,0.3)$ & $(0.2,0.4)$ & $(0.2,0.5)$ & $(0.6,0.3)$ & $(0.2,0.7)$ & $(0.4,0.5)$ \\
& $N_{5}$ & $(0.6,0.1)$ & $(0.7,0.3)$ & $(0.6,0.2)$ & $(0.5,0.2)$ & $(0.7,0.1)$ & $(0.6,0.4)$ \\
\hline & $N_{1}$ & $(0.8,0.1)$ & $(0.9,0.1)$ & $(0.7,0.2)$ & $(0.8,0.1)$ & $(0.6,0.3)$ & $(0.8,0.2)$ \\
& $N_{2}$ & $(0.6,0.2)$ & $(0.3,0.6)$ & $(0.4,0.3)$ & $(0.6,0.3)$ & $(0.7,0.2)$ & $(0.2,0.5)$ \\
$t_{3}$ & $N_{3}$ & $(0.6,0.3)$ & $(0.4,0.2)$ & $(0.4,0.3)$ & $(0.4,0.4)$ & $(0.6,0.3)$ & $(0.4,0.5)$ \\
& $N_{4}$ & $(0.5,0.4)$ & $(0.1,0.6)$ & $(0.2,0.6)$ & $(0.6,0.4)$ & $(0.2,0.6)$ & $(0.3,0.5)$ \\
& $N_{5}$ & $(0.7,0.1)$ & $(0.7,0.2)$ & $(0.6,0.3)$ & $(0.6,0.2)$ & $(0.5,0.2)$ & $(0.7,0.2)$ \\
\hline
\end{tabular}

Step 6. According to the DIFWG operator, the expert's personal dynamic evaluation matrix was integrated as Table 11. 
Table 11. Individual evaluation matrix for a period.

\begin{tabular}{cccccccc}
\hline \multirow{2}{*}{ Expert } & \multirow{2}{*}{ Design Partner } & \multicolumn{7}{c}{ EVALUATION INDEX } \\
\cline { 3 - 8 } & & $\boldsymbol{M}_{\mathbf{1}}$ & $\boldsymbol{M}_{\mathbf{2}}$ & $\boldsymbol{M}_{\mathbf{3}}$ & $\boldsymbol{M}_{\mathbf{4}}$ & $\boldsymbol{M}_{\mathbf{5}}$ & $\boldsymbol{M}_{\mathbf{6}}$ \\
\hline \multirow{3}{*}{1} & $(0.76,0.10)$ & $(0.60,0.20)$ & $(0.53,0.20)$ & $(0.70,0.20)$ & $(0.57,0.17)$ & $(0.73,0.15)$ \\
& $N_{1}$ & $(0.65,0.20)$ & $(0.37,0.53)$ & $(0.45,0.30)$ & $(0.60,0.30)$ & $(0.70,0.17)$ & $(0.20,0.72)$ \\
& $N_{2}$ & $(0.70,0.27)$ & $(0.33,0.50)$ & $(0.30,0.30)$ & $(0.70,0.40)$ & $(0.57,0.25)$ & $(0.37,0.50)$ \\
& $N_{3}$ & $(0.50,0.37)$ & $(0.16,0.57)$ & $(0.20,0.40)$ & $(0.60,0.30)$ & $(0.23,0.74)$ & $(0.34,0.57)$ \\
& $N_{4}$ & $(0.77,0.23)$ & $(0.53,0.30)$ & $(0.50,0.17)$ & $(0.53,0.20)$ & $(0.40,0.44)$ & $(0.49,0.41)$ \\
\hline & $N_{5}$ & $(0.84,0.10)$ & $(0.79,0.16)$ & $(0.74,0.20)$ & $(0.73,0.20)$ & $(0.60,0.23)$ & $(0.80,0.17)$ \\
& $N_{1}$ & $(0.57,0.23)$ & $(0.39,0.47)$ & $(0.57,0.23)$ & $(0.60,0.26)$ & $(0.57,0.13)$ & $(0.32,0.43)$ \\
& $N_{2}$ & $(0.67,0.25)$ & $(0.40,0.34)$ & $(0.30,0.30)$ & $(0.63,0.23)$ & $(0.57,0.25)$ & $(0.40,0.40)$ \\
& $N_{3}$ & $(0.50,0.29)$ & $(0.24,0.47)$ & $(0.20,0.36)$ & $(0.60,0.30)$ & $(0.25,0.41)$ & $(0.39,0.32)$ \\
& $N_{4}$ & $(0.74,0.13)$ & $(0.49,0.27)$ & $(0.56,0.25)$ & $(0.55,0.20)$ & $(0.40,0.39)$ & $(0.52,0.41)$ \\
\hline & $N_{5}$ & $(0.73,0.10)$ & $(0.75,0.14)$ & $(0.74,0.20)$ & $(0.73,0.20)$ & $(0.65,0.23)$ & $(0.83,0.13)$ \\
3 & $N_{1}$ & $(0.60,0.23)$ & $(0.37,0.47)$ & $(0.57,0.23)$ & $(0.60,0.26)$ & $(0.56,0.13)$ & $(0.32,0.37)$ \\
& $N_{2}$ & $(0.70,0.20)$ & $(0.40,0.31)$ & $(0.44,0.34)$ & $(0.59,0.27)$ & $(0.57,0.25)$ & $(0.40,0.43)$ \\
& $N_{3}$ & $(0.50,0.36)$ & $(0.18,0.47)$ & $(0.20,0.56)$ & $(0.60,0.33)$ & $(0.25,0.62)$ & $(0.39,0.47)$ \\
& $N_{4}$ & $(0.77,0.13)$ & $(0.63,0.24)$ & $(0.63,0.23)$ & $(0.56,0.20)$ & $(0.53,0.19)$ & $(0.56,0.35)$ \\
\hline
\end{tabular}

Step 7. According to the IFOWA operator, a comprehensive evaluation matrix for different experts is obtained (Table 12).

Table 12. The comprehensive evaluation matrix.

\begin{tabular}{ccccccc}
\hline \multirow{2}{*}{ Design Partner } & \multicolumn{7}{c}{ The Evaluation Index } \\
\cline { 2 - 7 } & $\boldsymbol{M}_{\mathbf{1}}$ & $\boldsymbol{M}_{\mathbf{2}}$ & $\boldsymbol{M}_{\mathbf{3}}$ & $\boldsymbol{M}_{\mathbf{4}}$ & $\boldsymbol{M}_{\mathbf{5}}$ & $\boldsymbol{M}_{\mathbf{6}}$ \\
\hline$N_{1}$ & $(0.76,0.10)$ & $(0.72,0.16)$ & $(0.48,0.20)$ & $(0.72,0.20)$ & $(0.62,0.22)$ & $(0.79,0.16)$ \\
$N_{2}$ & $(0.60,0.22)$ & $(0.37,0.49)$ & $(0.54,0.25)$ & $(0.60,0.27)$ & $(0.60,0.14)$ & $(0.29,0.51)$ \\
$N_{3}$ & $(0.69,0.25)$ & $(0.38,0.39)$ & $(0.33,0.31)$ & $(0.62,0.29)$ & $(0.57,0.25)$ & $(0.39,0.44)$ \\
$N_{4}$ & $(0.50,0.35)$ & $(0.19,0.50)$ & $(0.20,0.43)$ & $(0.60,0.31)$ & $(0.24,0.61)$ & $(0.38,0.46)$ \\
$N_{5}$ & $(0.75,0.16)$ & $(0.45,0.28)$ & $(0.54,0.20)$ & $(0.55,0.20)$ & $(0.43,0.36)$ & $(0.52,0.40)$ \\
\hline
\end{tabular}

After taking the different design phases into consideration, the evaluation process becomes more accurate and practical, so then we applied the proposed fuzzy KMA and fuzzy VIKOR to obtain a comprehensive and objective evaluation towards the design partner.

Step 8. According to Equations (13)-(19), the weight $w_{j}$ of index $M_{j}$ is obtained as follows: $(0.1765$, $0.1565,0.1586,0.1815,0.1611,0.1685)$.

Step 9. Obtain the score function matrix $S\left(\widetilde{a}_{i j}\right)$ according to Equation (2).

$$
S\left(\widetilde{a}_{i j}\right)=\left[\begin{array}{cccccc}
0.66 & 0.56 & 0.28 & 0.52 & 0.40 & 0.63 \\
0.38 & -0.12 & 0.29 & 0.33 & 0.46 & -0.22 \\
0.44 & -0.01 & 0.02 & 0.33 & 0.32 & -0.05 \\
0.15 & -0.31 & -0.23 & 0.29 & -0.37 & -0.08 \\
0.59 & 0.17 & 0.34 & 0.35 & 0.07 & 0.12
\end{array}\right]
$$

Step 10. A standardized evaluation matrix $S^{\prime}\left(\widetilde{a}_{i j}\right)$ was obtained according to Equation (19).

$$
S^{\prime}\left(\widetilde{a}_{i j}\right)=\left[\begin{array}{cccccc}
1 & 1 & 0.89 & 1 & 0.93 & 1 \\
0.45 & 0.22 & 0.91 & 0.17 & 1 & 0 \\
0.57 & 0.34 & 0.44 & 0.17 & 0.83 & 0.2 \\
0 & 0 & 0 & 0 & 0 & 0.16 \\
0.86 & 0.55 & 1 & 0.26 & 0.53 & 0.4
\end{array}\right]
$$


Step 11. According to Equations (20)-(22), $S_{i}, R_{i}$, and $Q_{i}$ were obtained as follows:

$$
S_{i}=\left[\begin{array}{l}
0.971 \\
0.450 \\
0.421 \\
0.027 \\
0.595
\end{array}\right] R_{i}=\left[\begin{array}{l}
0.182 \\
0.161 \\
0.134 \\
0.027 \\
0.159
\end{array}\right] Q_{i}=\left[\begin{array}{c}
1 \\
0.656 \\
0.554 \\
0 \\
0.736
\end{array}\right]
$$

Step 12. Sort according to the size of $Q_{i}$.

\section{Result Discussion and Comparative Analysis}

The proposed hybrid method provides a systemic analytical model for the improvement and selection of green product design partner. The model not only includes multiple criteria, but also considers the interdependencies among the criteria. According to the DEMATEL, the results in Table 7, indicate that D2 (financial strength $M_{1}$ ), D6 (service quality $M_{2}$ ), D8 (collaborative degree $M_{3}$ ), D11 (integrity degree $M_{4}$ ), D14 (the potential for long-term cooperation $M_{5}$ ), and D15 (green enterprise image $M_{6}$ ) are the most important criteria. However, we do not have insight into the importance order of each criterion, and what the weight these indices should be given in the decision-making process according to the decision rules where only the index greater than $Y_{c}{ }^{0}$ or $Y_{d}{ }^{o}$ can be retained. However, with the help of fuzzy KMA, we easily obtained the weight $w_{j}$ of index $M_{j}$, respectively as follows: $0.1765,0.1565,0.1586,0.1815,0.1611,0.1685$, which indicates that the integrity degree (D11) was the most important criterion, and the second was green enterprise image (D15). Next, the sorting result of the fuzzy VIKOR was $N_{1} \succ N_{5} \succ N_{2} \succ N_{3} \succ N_{4}$. From the perspective of environmental, economic, and the sustainable development of enterprises, we know that $N_{1}$ is the most suitable design partner.

To verify the validity of the developed method, we completed its comparative analysis with the GRA (Grey relational analysis) method [62] and TOPSIS method based on entropy weight angle [63].

\section{(1) Grey relational analysis (GRA)}

GRA is a multifactor statistical analysis method. It takes the sample data of each factor as the basis, and describes the intensity, magnitude, and order of the relations among factors by grey conjunction. We can obtain the correlation coefficient of each $\xi_{i j}$ according to the following formula:

$$
\xi_{i j}=\frac{\min _{i} \min _{j}\left|x^{*}{ }_{j}-x_{i j}\right|+\rho \max _{i} \max _{j}\left|x^{*}{ }_{j}-x_{i j}\right|}{\left|x^{*}{ }_{j}-x_{i j}\right|+\rho \max _{i} \max _{j}\left|x^{*}{ }_{j}-x_{i j}\right|}
$$

where $x^{*}{ }_{j}$ represents the maximum value of $X_{j}$.

$$
\xi_{i}=\frac{1}{m} \sum_{j=1}^{m} \xi_{i j}
$$

From the data of matrix $S^{\prime}\left(\widetilde{a}_{i j}\right)$, we obtain

$$
\xi_{i j}=\left[\begin{array}{llllll}
1.0000 & 1.0000 & 0.8297 & 1.0000 & 0.8772 & 1.0000 \\
0.4762 & 0.3906 & 0.8475 & 0.3759 & 1.0000 & 0.3333 \\
0.5376 & 0.4310 & 0.4717 & 0.3759 & 0.7463 & 0.3846 \\
0.3333 & 0.3333 & 0.3333 & 0.3333 & 0.3333 & 0.3731 \\
0.7813 & 0.5263 & 1.0000 & 0.4032 & 0.5155 & 0.4545
\end{array}\right]
$$


where $\xi_{i j}$ is the correlation coefficient of each index. Then, we can obtain the grey relational order $\xi_{i}=(0.9495,0.5706,0.4912,0.3400,0.6135)^{T}$ according to Equation (24). The greater the value, the better the scheme.

(2) The improved TOPSIS

TOPSIS is a sort method based on the positive and negative ideal solution. It sorts order according to the relative closeness. The greater the relative closeness is, the result of the TOPSIS method based on entropy weight angle can be obtained by the following equations:

$$
\begin{gathered}
\vartheta_{i}^{+}=\arccos \frac{v^{+} v_{i}^{T}}{\left\|v_{i}\right\| v^{+} \|} \\
\vartheta_{i}^{-}=\arccos \frac{v^{-} v_{i}^{T}}{\left\|v_{i}\right\| v^{-} \|} \\
c_{i}=\frac{\vartheta_{i}^{-}}{\vartheta_{i}^{-}+\vartheta_{i}^{+}}
\end{gathered}
$$

where $v_{i}$ represents the evaluation vector of the $i$ th design partner, $v^{+}$is the vector for the positive ideal solution, the corresponding $v^{-}$represents the negative one, and $c_{i}$ is the relative closeness. From the data of matrix $S^{\prime}\left(\widetilde{a}_{i j}\right)$, we obtained $c_{i}=(1,0.6166,0.7432,0,1)$. Table 13 shows the calculation results of the above methods.

Table 13. Comparison of results of several methods.

\begin{tabular}{cccc}
\hline Method & Proposed Method & GRA & Improved TOPSIS \\
\hline Order & $1>5>2>3>4$ & $1>5>2>3>4$ & $1 \approx 5>3>2>4$ \\
\hline
\end{tabular}

From the above table, we can see that the sorted result of the proposed MADM model was the same as that of GRA, and had little difference with the TOPSIS method based on entropy weight angle in the meantime. The reason is that the proposed method and GRA take full account of the interaction between the data so that the results are more accurate than TOPSIS, which relies solely on the data itself. Nevertheless, our method took full account of the dynamic time factors, and also reduced the influence of the limited rationality of the experts. The comparison showed that the best choice was $N_{1}$, and the validity of the proposed MADM model was verified.

\section{Conclusions}

This paper proposed a two-stage dynamic novel hybrid MADM model to select a design partner for new energy automobile manufacturing enterprises. The main conclusions and relevant prospects of the proposed model are as follows:

(1) The combination of fuzzy DEMATEL, fuzzy KMA, and fuzzy VIKOR used in this paper offered a more precise analysis method for alternatives, i.e., green product design partners or green suppliers. It provided an objective and comprehensive new method and idea for the actual production enterprises to choose partners that meet their own requirements of sustainable development and green concept, and also provides some references for product design and manufacturing enterprises.

(2) Some suggestions and lessons emerged from this study. For managers, they should enhance three aspects of the enterprise, i.e., integrity degree, financial strength, and green enterprise image to find excellent collaborators and produce competitive green products.

(3) While it is believed that the presented model provides value, there are also further points that can be included. On the one hand, with fuzzy language and fuzzy sets, it is possible to reduce 
the impact of expert scoring, but it is still impossible to avoid subjective influence, so further studies should consider how to avoid bias due to the subjective preferences of the experts. On the other hand, the dynamics of this paper were reflected from different production stages, so future research could continue to study this issue in terms of time factors such as the impact of continuous time change (not a certain time period) on the results and how to evaluate and make decisions.

Acknowledgments: The study was supported by the "National Natural Science Foundation of China" (71401131), the "MOE (Ministry of Education in China) Project of Humanities and Social Sciences" (13XJC630011), the "Research Fund from Key Laboratory of computer integrated manufacturing in Guangdong Province" (CIMSOF2016002), the "State Key Laboratory for Manufacturing Systems Engineering (Xi'an Jiaotong University)" (sklms2017005), the "China Postdoctoral Science Foundation funded project" (2016M590929), and the "Shaanxi Natural Science Foundation Project" (2017JM7004).

Author Contributions: Haiyang Liu developed the model and wrote the draft for this paper. Yaxuan Xiao and Hui Lu collected the raw data, and helped revise the written draft. Aijun Liu was the thesis advisor; he revised the written draft and provided theoretical and technical guidance during the completion of the paper. Sang-Bing Tsai provided revised advice.

Conflicts of Interest: The authors declare no conflict of interest.

\section{References}

1. Dain, M.A.L.; Calvi, R.; Cheriti, S. Measuring supplier performance in collaborative design: Proposition of a framework. Res. Dev. Manag. 2011, 41, 61-79.

2. Camarinha-Matos, L.M.; Afsarmanesh, H. Collaborative networks: Anew scientific discipline. J. Intell. Manuf. 2005, 16, 439-452. [CrossRef]

3. Camarinha-Matos, L.M.; Afsarmanesh, H.; Galeano, N.; Molina, A. Collaborative networked organizations-Concepts and practice in manufacturing enterprises. Comput. Ind. Eng. 2009, 57, 46-60. [CrossRef]

4. Qu, Q.; Tsai, S.; Tang, M.; Xu, C.; Dong, W. Marine Ecological Environment Management Based on Ecological Compensation Mechanisms. Sustainability 2016, 8, 1267. [CrossRef]

5. Qu, Q.; Wang, W.; Tang, M.; Lu, Y.; Tsai, S. A Performance Evaluation Study of Human Resources in Low-Carbon Logistics Enterprises. Sustainability 2017, 9, 632. [CrossRef]

6. Ge, B.; Jiang, D.; Gao, Y.; Tsai, S. The Influence of Legitimacy on a Proactive Green Orientation and Green Performance: A Study Basedon Transitional Economy Scenarios in China. Sustainability 2016, 8, 1344. [CrossRef]

7. Carter, C.R.; Easton, P.L. Sustainable supply chain management: Evolution and future directions. Int. J. Phys. Distrib. Logist. Manag. 2015, 41, 46-62. [CrossRef]

8. Centobelli, P.; Cerchione, R.; Esposito, E. Environmental sustainability in the service industry of transportation and logistics service providers: Systematic literature review and research directions. Transp. Res. Part D Trans. Environ. 2017, 53, 454-470. [CrossRef]

9. Correia, E.; Carvalho, H.; Azevedo, S.; Govindan, K. Maturity models in supply chain sustainability: A systematic literature review. Sustainability 2017, 9, 64. [CrossRef]

10. Mollenkopf, D.; Stolze, H.; Tate, W.L.; Ueltschy, M. Green, lean, and global supply chains. Int. J. Phys. Distrib. Logist. Manag. 2010, 40, 14-41. [CrossRef]

11. Touboulic, A.; Walker, H. Theories in sustainable supply chain management: A structured literature review. Int. J. Phys. Distrib. Logist. Manag. 2015, 45, 16-42. [CrossRef]

12. Liu, B.; Li, T.; Tsai, S.-B. Low Carbon Strategy Analysis of Competing Supply Chains with Different Power Structures. Sustainability 2017, 9, 835. [CrossRef]

13. Huang, Z.; Nie, J.; Tsai, S.-B. Dynamic Collection Strategy and Coordination of a Remanufacturing Closed-Loop Supply Chain under Uncertainty. Sustainability 2017, 9, 683. [CrossRef]

14. Cui, W.; Ze, X.; Li, G. A new process modeling method for product collaborative design. In Proceedings of the 2009 International Conference on Information Management, Innovation Management and Industrial Engineering, Xi'an, China, 26-27 December2009.

15. Huang, H.Z.; Liu, W.; Li, L. Process modeling of product collaborative design. Comput. Integr. Manuf. Syst. 2003, 9, 955-959. 
16. Feng, G.; Cui, D.; Wang, C.; Yu, J. Integrated data management in complex product collaborative design. Comput. Ind. 2009, 60, 48-63. [CrossRef]

17. Xing, Q.S.; Yang, Y.; Liu, A.J.; Guo-dong, Y. Coordination efficiency considered accident in product collaborative design task. Syst. Eng. Theory Pract. 2014, 34, 1043-1051.

18. Yang, G.D.; Yang, Y.; Zhang, X.; Aijun, L. Multi-objective dynamic fuzzy scheduling and its algorithm in product collaborative design considering emergency. J. Intell. Fuzzy Syst. 2015, 29, 1355-1365.

19. Liu, A.; Hu, H.; Zhang, X.; Lei, D. Novel two-phase approach for process optimization of customer collaborative design based on fuzzy-QFD and DSM. IEEE Trans. Eng. Manag. 2017, 64, 193-207. [CrossRef]

20. Zhu, J.; Song, X.D. A conflict detection algorithm based on the design history in collaborative CAD design. Comput. Digit. Eng. 2012, 5, 79-81.

21. Hepworth, A.; Tew, K.; Trent, M.; Ricks, D.; Jensen, C.G.; Red, W.E. Model consistency and conflict resolution with data preservation in multi-user computer aided design. J. Comput. Inf. Sci. Eng. 2014, 14, 021008. [CrossRef]

22. Cheng, Y.; He, F.; Wu, Y.; Zhang, D. Meta-operation conflict resolution for human-human interaction in collaborative feature-based CAD systems. Clust. Comput. 2016, 19, 237-253. [CrossRef]

23. Yang, K.; Wu, S.; Zhou, L. A conflict detection model based on constraint satisfaction in food product collaborative design. Adv. J. Food Sci. Technol. 2016, 10, 37-42. [CrossRef]

24. Park, J.H.; Seo, K.K. A knowledge-based approximate life cycle assessment system for evaluating environmental impacts of product design alternatives in a collaborative design environment. Adv. Eng. Inform. 2006, 20, 147-154. [CrossRef]

25. Tian, Z.P.; Wang, J.; Wang, J.Q.; Zhang, H.Y. Simplified neutrosophic linguistic multi-criteria group decision-making approach to green product development. Group Decis. Negot. 2017, 26, 597-627. [CrossRef]

26. Zhu, W.; He, Y. Green product design in supply chains under competition. Eur. J. Oper. Res. 2017, 258, 165-180. [CrossRef]

27. Leonidou, L.C.; Christodoulides, P.; Kyrgidou, L.P.; Palihawadana, D. Internal drivers and performance consequences of small firm green business strategy: The moderating role of external forces. J. Bus. Ethics 2017, 140, 585-606. [CrossRef]

28. Dangelico, R.M. Green product innovation: Where we are and where we are going. Bus. Strat. Environ. 2016, 25, 560-576. [CrossRef]

29. Chandrasegaran, S.K.; Ramani, K.; Sriram, R.D.; Horváth, I.; Bernard, A.; Harik, R.F.; Gao, W. The evolution, challenges, and future of knowledge representation in product design systems. Comput. Aided Des. 2013, 45, 204-228. [CrossRef]

30. Mardani, A.; Jusoh, A.; Nor, K.M.; Khalifah, Z.; Zakwan, N.; Valipour, A. Multiple criteria decision-making techniques and their applications-A review of the literature from 2000 to 2014. Econ. Res. 2015, 28, 516-571. [CrossRef]

31. Zavadskas, E.K.; Govindan, K.; Antucheviciene, J.; Turskis, Z. Hybrid multiple criteria decision-making methods: A review of applications for sustainability issues. Ekon. Istraž. 2016, 29, 857-887. [CrossRef]

32. Govindan, K.; Rajendran, S.; Sarkis, J.; Murugesan, P. Multi criteria decision making approaches for green supplier evaluation and selection: A literature review. J. Clean. Prod. 2015, 98, 66-83. [CrossRef]

33. Chang, B.; Chang, C.W.; Wu, C.H. Fuzzy DEMATEL method for developing supplier selection criteria. Expert Syst. Appl. 2011, 38, 1850-1858. [CrossRef]

34. Hsu, C.W.; Kuo, T.C.; Chen, S.H.; Hu, A.H. Using DEMATEL to develop a carbon management model of supplier selection in green supply chain management. J. Clean. Prod. 2013, 56, 164-172. [CrossRef]

35. Lin, R.J. Using fuzzy DEMATEL to evaluate the green supply chain management practices. J. Clean. Prod. 2013, 40, 32-39. [CrossRef]

36. Mendel, J.M. On KM algorithms for solving type-2 fuzzy set problems. IEEE Trans. Fuzzy Syst. 2013, 21, 426-446. [CrossRef]

37. Salaken, S.M.; Khosravi, A.; Nahavandi, S. Modification on enhanced Karnik-Mendel algorithm. Expert Syst. Appl. 2016, 65, 283-291. [CrossRef]

38. Chen, C.; John, R.; Twycross, J.; Garibaldi, J. A direct approach for determining the switch points in the Karnik-Mendel algorithm. IEEE Trans. Fuzzy Syst. 2017. [CrossRef]

39. Shemshadi, A.; Shirazi, H.; Toreihi, M.; Tarokh, M.J. A fuzzy VIKOR method for supplier selection based on entropy measure for objective weighting. Expert Syst. Appl. 2011, 38, 12160-12167. [CrossRef] 
40. Sanayei, A.; Mousavi, S.F.; Yazdankhah, A. Group decision making process for supplier selection with VIKOR under fuzzy environment. Expert Syst. Appl. 2010, 37, 24-30. [CrossRef]

41. You, X.Y.; You, J.X.; Liu, H.C.; Zhen, L. Group multi-criteria supplier selection using an extended VIKOR method with interval 2-tuple linguistic information. Expert Syst. Appl. 2015, 42, 1906-1916. [CrossRef]

42. Boran, F.E.; Genç, S.; Kurt, M.; Akay, D. A multi-criteria intuitionistic fuzzy group decision making for supplier selection with TOPSIS method. Expert Syst. Appl. 2009, 36, 11363-11368. [CrossRef]

43. Wang, J.W.; Cheng, C.H.; Huang, K.C. Fuzzy hierarchical TOPSIS for supplier selection. Appl. Soft Comput. 2009, 9, 377-386. [CrossRef]

44. Zouggari, A.; Benyoucef, L. Simulation based fuzzy TOPSIS approach for group multi-criteria supplier selection problem. Eng. Appl. Artif. Intell. 2012, 25, 507-519. [CrossRef]

45. Güngör, Z.; Serhadlığlu, G.; Kesen, S.E. A fuzzy AHP approach to personnel selection problem. Appl. Soft Comput. 2009, 9, 641-646. [CrossRef]

46. Kilincci, O.; Onal, S.A. Fuzzy AHP approach for supplier selection in a washing machine company. Expert Syst. Appl. 2011, 38, 9656-9664. [CrossRef]

47. Guneri, A.F.; Cengiz, M.; Seker, S. A fuzzy ANP approach to shipyard location selection. Expert Syst. Appl. 2009, 36, 7992-7999. [CrossRef]

48. Bhattacharya, A.; Mohapatra, P.; Kumar, V.; Dey, P.K.; Brady, M.; Tiwari, M.K.; Nudurupati, S.S. Green supply chain performance measurement using fuzzy ANP-based balanced scorecard: A collaborative decision-making approach. Prod. Plan. Control 2014, 25, 698-714. [CrossRef]

49. Büyüközkan, G.; Çifçi, G. Evaluation of the green supply chain management practices: A fuzzy ANP approach. Prod. Plan. Control 2012, 23, 405-418. [CrossRef]

50. Zavadskas, E.K.; Antucheviciene, J.; Turskis, Z.; Adeli, H. Hybrid multiple-criteria decision-making methods: A review of applications in engineering. Sci. Iran. 2016, 23, 1-20.

51. KeshavarzGhorabaee, M.; Amiri, M.; Zavadskas, E.K.; Antucheviciene, J. Supplier evaluation and selection in fuzzy environments: A review of MADM approaches. Econ. Res. 2017, 30, 1073-1118.

52. Freeman, J.; Chen, T. Green supplier selection using an AHP-Entropy-TOPSIS framework. Supply Chain Manag. 2015, 20, 327-340. [CrossRef]

53. Kar, A.K. A hybrid group decision support system for supplier selection using analytic hierarchy process, fuzzy set theory and neural network. J.Comput. Sci. 2015, 6, 23-33. [CrossRef]

54. Büyüközkan, G.; Çifçi, G. A novel hybrid MCDM approach based on fuzzy DEMATEL, fuzzy ANP and fuzzy TOPSIS to evaluate green suppliers. Expert Syst. Appl. 2012, 39, 3000-3011. [CrossRef]

55. Tadić, S.; Zečević, S.; Krstić, M. A novel hybrid MCDM model based on fuzzy DEMATEL, fuzzy ANP and fuzzy VIKOR for city logistics concept selection. Expert Syst. Appl. 2014, 41, 8112-8128. [CrossRef]

56. Liou, J.J.; Tamošaitienè, J.; Zavadskas, E.K.; Tzeng, G.H. New hybrid COPRAS-G MADM Model for improving and selecting suppliers in green supply chain management. Int. J. Prod. Res. 2016, 54, 114-134. [CrossRef]

57. Yazdani, M.; Chatterjee, P.; Zavadskas, E.K.; Zolfani, S.H. Integrated QFD-MCDM framework for green supplier selection. J. Clean. Prod. 2017, 142, 3728-3740. [CrossRef]

58. Kutlu, A.C.; Ekmekçioğlu, M. Fuzzy failure modes and effects analysis by using fuzzy TOPSIS-based fuzzy AHP. Expert Syst. Appl. 2012, 39, 61-67. [CrossRef]

59. Han, S.; Liu, X. Global convergence of Karnik-Mendel algorithms. Fuzzy Sets Syst. 2016, 283, $108-119$. [CrossRef]

60. Mardani, A.; Zavadskas, E.K.; Govindan, K.; AmatSenin, A.; Jusoh, A. VIKOR technique: A systematic review of the state of the art literature on methodologies and applications. Sustainability 2016, 8, 37. [CrossRef]

61. Xu, Z. An overview of methods for determining OWA weights. Int. J. Intell. Syst. 2005, 20, 843-865. [CrossRef]

62. Jia, Z.Y.; He, B. Grid Material supplier selection based on entropy weight correction from perspective of low carbon. Appl. Mech. Mater. 2014, 618, 603-607. [CrossRef]

63. Hashemi, S.H.; Karimi, A.; Tavana, M. An integrated green supplier selection approach with analytic network process and improved grey relational analysis. Int. J. Prod. Econ. 2015, 159, 178-191. [CrossRef]

(C) 2018 by the authors. Licensee MDPI, Basel, Switzerland. This article is an open access article distributed under the terms and conditions of the Creative Commons Attribution (CC BY) license (http:/ / creativecommons.org/licenses/by/4.0/). 